\title{
Amodified Lou-Huh model for characterization of ductile fracture of DP590 sheet
}

\author{
C. Cheng, B. Meng*, J.Q. Han, M. Wan,X.D. Wu,R. Zhao
}

School of Mechanical Engineering \& Automation, Beihang University, Beijing 100191, P.R.China

*Corresponding author. Tel: +861082338613. E-mail address: mengbao@buaa.edu.cn

\begin{abstract}
In this paper, a modified ductile fracture criterion was established to predict the fracture behavior of DP590 sheet based on Lou-Huh model.Considering the change of loading path duringthe plastic forming process, the $\mathrm{C}-\mathrm{H}$ model was introduced tointerpret the whole loading history. According to $\mathrm{C}-\mathrm{H}$ model, the plastic loading process is divided into three stages including homogeneous deformation, deformation localization and localized instability. In addition, the variations of stress triaxiality and Lode parameter weretracked by the corresponding stress ratiosunder three tensile deformation patterns including uniaxial tension, plane strain tension and equi-biaxial tension.Based on the optimization algorithm, the material constantsof the original and modified Lou-Huh fracture criteriawere determined and their theoretical fracture limit strainswere compared with the experimental one.Furthermore, the morphology of fracture surfaces was also taken to characterize the ductile fracture behavior of DP590 sheet.Resultsshowed that the modified Lou-Huh model is more suitable for the prediction of ductile fracture of DP590 sheet, andthe growth and shear coalescence of microvoids are correlated with stress triaxiality and Lode parameter, which change with the development of plastic deformation.
\end{abstract}

Keywords:High strength steel, Fracture limit, C-H model, Ductile fracture criterion, Loading path. 


\section{Introduction}

With the advancement of automobile industry, especially the trend towards energy saving, environment protection and enhanced crash performance for the vehicles, the ubiquitous use of advanced high strength steel (AHSS) is facilitateddue to its high strength and good formability. However, compared with other conventional steel sheets, the application of AHSS is limited by its complex fracture behavior[1]. Thesheet metal formabilityis usually assessed via the forming limit diagram (FLD), which is an important performance indicator used to predict localized necking in the field of sheet forming.The FLDcan be determined by corresponding plastic instability theory based on the onset of through-thickness necking of sheet.Because the fracture of AHSS often occurs without obvious necking phenomenon, the conventional plastic instability theories areno longer suitable for the failure prediction.Thus many researchers [2-4] employed the fracture limit diagram (FFLD) to describe the deformation achievable of sheet metal controlled by fracture, which can be obtained by the ductile fracture criteria.

In the process ofsheet metal forming, the plastic deformation stage which occurs after through-thickness necking should be considered in the study of ductile damage and fracture.In addition,the fracture phenomenon ofsome materialsmay take place prior to failure caused by localized necking. To consider the above two cases, a suitable ductile fracture criterion (DFC) is vital for the precision prediction of the failure pattern of AHSS sheet. Fromthe micro-level viewpoint, ductile fracture of metal is the combinedresults of nucleation, growth and coalescence of microscopic voids[5]. On the one hand, some damage models coupled with the constitutive equationare used to describe both plasticity and ductile fracture of porous materials based on the damage accumulation mechanism. For example, theGTN model was proposed and developed by Gurson[6], Tvergaard and Needleman[7], which is a porous plasticity model in terms of the micromechanical analysis of a thick spherical shell subjected to hydrostatic pressure.Recently, the inaccuracy of GTN model for the shear-dominated stress state has been validated by Xue[8],Nielsen and 
Tvergaard[9].Another coupled ductile fracture criterion is dependent on the continuum damage mechanics (CDM), which is proposed by Lemaitre[10]. On the other hand, phenomenologicalductile fracture criteria are uncoupled with the plasticity formulation, which are particularly popular in engineering practice because of their simplicity and less material constants to be calibrated. The fracture is assumed to occur when the material critical damage value is reached. At present, the uncoupled fracture criteria are also used to predict the ductile fracture and deformation behavior in progressive microforming[11].

The early work ofphenomenological ductile fracture criteriafocused onthe effect of stress triaxiality, which is expressed as the ratio of the hydrostatic stress to von Mises equivalent stress, on the ductile fracture of the used material. Many investigatorsfound thatthe material ductility usually decreases withthe increase of stress triaxiality.The workof Hancock and Mackenzierevealedthattheductile fracture clearly depends on the triaxiality of stress state via performing a series of tensile tests[12]. Johnson and Cook carried out a great deal of experimental studies on various materials and introduced a cumulative-damage fracture model, which works well over the positive range of the stress triaxiality values[13].Mirza et al. [14] implemented the notched tensile tests and numerical simulations on three different materials, anddiscovered that the ductilities of all the three materials are strongly rootedin the level of stress triaxiality.Subsequently,several recentresearchesindicated that Lode parameter, which is associated with the third invariant of deviator stress tensor, also playsa crucial role in ductile damage and fracture, especially in low stress triaxiality scenario. Bai and Wierzbicki[15] modified the Mohr-Coulomb model and defined the fracture strain as the function of stress triaxiality and Lode parameter in plane stress condition. The modified criterion could predict all the experimental points well.According to the investigations ofDanas [16] and Brünig[17], the stress state obviously affectsthe fracture behavior anddamage mechanism of the used material.Likethe stress triaxiality, Lode parameter isalsoan important factor to control the initiation and evolution of ductile damage and fracture.Base on the interactive effect of stress triaxiality and Lode parameter, Lou et al. [18] proposed a micro-mechanism-motivated macroscopic 
ductile fracture criterionconsidering the combination of stress triaxiality and Lode parameter to describe the ductile fracture behaviorof sheet metal.

The determination of material constants of ductile fracture criteriondepends on the corresponding magnitudes of stress triaxiality and Lode parameter, which are usually obtained by a combined experimental-numerical method. Currently,the average values, initial values or final values of the two parameters during the plastic deformation process up to the onset of ductile fracture were adopted by many scholars[2, 19, 20]. However, the fracture initiation is an evolutionary process, the stress state changes dramatically since all the prior loading paths become plane strain state $\left(d \varepsilon_{2}=0\right)$ after the occurrence of diffusenecking[21]. Based on Marciniak-Kuczynski (M-K) model[22], Ding[23] and Friedman[24]demonstrated that the loading path in the groove steadilydevelopsfrom a certain momenttothe state of plane strain.Qian[25] andLi[26]proved thatstress triaxiality and Lode parameter not only change withthe equivalent plastic strain but also have a close relationship with the distribution of plasticstrain. In the study of Park[4], the effect of the changeof loading path was taken into account inthe calibration of material constantsof ductile fracture criterion.Due to the dependence of stress triaxiality and Lode parameter on the loading history, the construction of fracture limit diagram based on the invariable parameterswasthus inappropriate and inaccurate.

In this research, the fracture behavior of DP590sheetwascharacterized, and a modified Lou-Huh modelwas proposed to predict its fracture limit strains considering the dependence of stress triaxiality and Lode parameter on the loading history.The $\mathrm{C}-\mathrm{H}$ model[27]was applied to describe the variation of stress ratio for the three typical loading cases including uniaxial tension, plane strain tension and equi-biaxial tension.Combining with the optimization algorithm, the material constants of original and modified Lou-Huh model were calculated. The corresponding fracture locus of DP590 sheetwereconstructed and compared with the experimental one.Meanwhile, the characterization of ductile fracture of DP590 sheetwasinvestigated and discussed via SEM images of fracture surfaces. 


\section{Material and methodology}

The material adopted in the research was dual-phase steel DP590 with thickness of $1.5 \mathrm{~mm}$, which was produced by BaoSteel Inc.The material has the typical DP structure consisting of ferrite and martensite islands. The chemical compositionsof DP590 sheet(weight percent) weresummarized inTable 1.To get the mechanical properties of DP590 sheet, the uniaxial tensile tests were performed on the Instron tensile test machine. The material properties were listed inTable 2.Fig. 1showed the true stress-strain curves from tensile tests along $0^{\circ}, 45^{\circ}$ and $90^{\circ}$ to the rolling direction.From Fig. 1, it could be observed thatDP590 sheet exhibits slight difference of mechanical properties in three testing directions. For simplicity, the planar isotropy of DP590 sheet is assumed, the average normal anisotropic coefficient $r$-value equals to 0.922 .

The research procedure was summarized inFig. 2. The Lou-Huh ductile fracture criterion was modified by incorporating Hill'48 yield function and C-H model which can describe the variation of loading path. Based on three typical tensile tests and optimization algorithm, the material constants in the original and modified Lou-Huh ductile fracture criteria were calculated and their correspondingFFLD were compared with the experimental result.

\subsection{C-H model}

\subsubsection{General description}

The loading path instability theory was originally proposed by Chen and $\mathrm{Hu}$, calledC-H model. Unlike M-K model which considers that the localized instability is caused by the surface defects of sheet metal, C-H model argues that the occurrence of localized instability of sheet metal is a gradual process and the evolution of internal damage promotes the transformation ofloading path from stress states between uniaxial tension and equi-biaxial tensionto plane strain state.According to C-H model, plastic deformation process is decomposedinto three phases as schematically shown inFig. 3. 
PhaseI:Homogeneous deformation up to load instability(abSection);

Phase II:Deformation localization with the transformation of loading pathunder constant load(bcSection);

Phase III:Localized instability or macroscopic crack appearing with the suddendrop of load.

The ability of this model to predict FFLDhas been discussed by several researchers. For example,Chen and $\mathrm{Hu}$ [28]employed $\mathrm{C}-\mathrm{H}$ model to calculate the fracture limit strain of aluminum alloy based on Hosford yield criterion.According to Xie's research[29], the fracture limit diagram determined by $\mathrm{C}-\mathrm{H}$ model was compared with that predicted by M-K model, Swift and Hill instability theories. Based on the above studies,it was found that the deviationbetween the theoretical and experimental FFLDs near plane strain state can not be neglected, which may be attributed to the assumption of the condition of localized instability.In the original $\mathrm{C}-\mathrm{H}$ model,the occurrence of localized instability $\left(d \varepsilon_{2}=0\right)$ is taken as a fracture criterion,and the diffuse and localized instabilitiesare considered to appear simultaneously under plane strain state.

To precisely describe the plastic deformation behavior andductile fracture characteristic of DP590 sheet under various stress states,C-H model was adopted to reflect the change of loading path before fracture in the research.

\subsubsection{Plasticity relationship}

Due to the fact that the employed yield function has a significant impact on the prediction of the forming behavior of DP590 sheet, the biaxial tensile tests and cruciform specimens[30] were adopted to obtain the plastic work contour of DP590 sheet, which is considered as yield locus. The experimental yield locus of DP590 sheet and the theoretical yield loci based on Hill'48, Hosford, Barlat'89, Yld2000-2d yield criteria are shown in Fig. 4. It is found that Barlat'89 yield criterion has the closest agreement with the experimental one. Although its accuracy for describing yield locus is slightly lower than Barlat'89 and Yld2000-2d yield functions, Hill'48 yield criterion was employed in this study for the purpose of simplifying calculation. 
Under plane stress state $\left(\sigma_{3}=0\right)$, Hill'48 yield functionand its corresponding equivalent plastic strain could been written asEqs. (1)and (2).

$$
\begin{gathered}
\sigma_{1}^{2}-\frac{2 r}{1+r} \sigma_{1} \sigma_{2}+\sigma_{2}^{2}=\sigma_{e}^{2} \\
\varepsilon_{e}=\frac{1+r}{\sqrt{1+2 r}}\left(\varepsilon_{1}^{2}+\frac{2 r}{1+r} \varepsilon_{1} \varepsilon_{2}+\varepsilon_{2}^{2}\right)^{1 / 2}
\end{gathered}
$$

where $\sigma_{e}$ represents the yield stress; $r$ is the average normal anisotropic coefficient.

According to Eq.(1), the following equation isobtained,

$$
\varphi=\frac{\sigma_{e}}{\sigma_{1}}=\sqrt{1-\frac{2 r}{1+r} \alpha+\alpha^{2}}
$$

whereais the loading path defined as the ratio of the minorprincipal stress $\sigma_{2}$ to the major principal stress $\sigma_{1}$ under the plane stress condition.

Based on the hypothesis of the associated flow rule, the relationship between the plastic strain increments is described as,

$$
\frac{d \varepsilon_{1}}{\varphi_{1}}=\frac{d \varepsilon_{2}}{\varphi_{2}}=\frac{d \varepsilon_{3}}{\varphi_{3}}=\frac{d \varepsilon_{e}}{\varphi}
$$

where $\varphi_{1}=1-\frac{r}{1+r} \alpha ; \quad \varphi_{2}=\alpha-\frac{r}{1+r} ; \quad \varphi_{3}=-\left(\varphi_{1}+\varphi_{2}\right)=-\frac{1+\alpha}{1+r}$.

\subsubsection{Phase I: Homogeneous deformation zone}

During this stage,homogeneous deformation is assumed until the load instability occurs. With the proceeding of deformation, the loading path remains linear. Therefore, the strain of this stage can be calculated by the total strain theory of plasticity.Theload instability criterionin the direction of the major principal stressis described by Considere-type criterion[31], as the load acting on the sheet cross section attains its maximum $\left(d P_{1}=0\right)$, that is formulated as:

$$
\frac{d \sigma_{1}}{\sigma_{1}}=d \varepsilon_{1}
$$

Considering the power exponent hardening law,

$$
\sigma_{e}=k \varepsilon_{e}^{n}
$$

where $k$ and $n$ are the strength coefficient and strain hardening exponent, respectively. The following equation is achieved by combining Eqs. (5) with (6), 


$$
d \sigma_{e}=k n \varepsilon_{e}^{n-1} d \varepsilon_{e}=\sigma_{e} \frac{n}{\varepsilon_{e}} d \varepsilon_{e}
$$

During the steady loading stage, the material deformation resistance is equal to the stress increment:

$$
d \sigma_{e}=\beta_{1} d \sigma_{1}+\beta_{2} d \sigma_{2}
$$

where $\beta_{1}=\frac{\partial \sigma_{e}}{\partial \sigma_{1}}=\frac{\varphi_{1}}{\varphi}, \beta_{2}=\frac{\partial \sigma_{e}}{\partial \sigma_{2}}=\frac{\varphi_{2}}{\varphi}$.

Based on the assumption of homogeneous deformation, the following relationship is obtained:

$$
\frac{d \sigma_{2}}{d \sigma_{1}}=\frac{\sigma_{2}}{\sigma_{1}}=\alpha
$$

In terms of the associated flow rule and the total strain theory of plasticity, the ratios of plastic strains areexpressed as:

$$
\begin{aligned}
& \frac{\varepsilon_{e}}{\varepsilon_{1}}=\frac{d \varepsilon_{e}}{d \varepsilon_{1}}=\frac{\varphi}{\varphi_{1}} \\
& \frac{\varepsilon_{2}}{\varepsilon_{1}}=\frac{d \varepsilon_{2}}{d \varepsilon_{1}}=\frac{\varphi_{2}}{\varphi_{1}}
\end{aligned}
$$

Substituting Eqs. (3),(5), (7), (9) and(10) into Eq.(8), the strains of Phase I can be deduced as follows:

$$
\begin{aligned}
\varepsilon_{e} & =\frac{\varphi}{\varphi_{1}} n \\
\varepsilon_{1} & =n \\
\varepsilon_{2} & =\frac{\varphi_{2}}{\varphi_{1}} n
\end{aligned}
$$

\subsubsection{Phase II:Deformation localization zone}

After reaching the maximum load, the load in the direction of the major principal stressof Phase II still remains constant.It indicates that Eq.(5) not only characterizes the end of PhaseI, but also keeps valid throughout Phase II. Due to the deformation restriction and discontinuity caused by theevolution of damage, the loading path gradually drifts to the plane strain state during Phase II. Consequently, the strainsare composed of two parts. The first part is the strain of PhaseI and the second onecan be calculated by numerical iterative algorithm based on elastic-plastic incremental strain theory. Furthermore, the hypothesis of load constancyduring Phase II has been 
verified by the experimentperformed by Chamanfar and Mahmudi[32].Combining Eqs. (5), (7)with(8), the following relationship is obtained,

$$
d \sigma_{2}=\frac{1}{\beta_{2}}\left(\frac{n}{\varepsilon_{e}} \sigma_{e} d \varepsilon_{e}-\beta_{1} \sigma_{1} d \varepsilon_{1}\right)
$$

Thus,

$$
\left\{\begin{array}{l}
d \sigma_{2}=\left(\frac{n}{\varepsilon_{e}} \varphi-\beta_{1} \frac{\varphi_{1}}{\varphi}\right) \frac{\sigma_{1} d \varepsilon_{e}}{\beta_{2}} \\
d \sigma_{1}=\sigma_{1} d \varepsilon_{1}=\frac{\varphi_{1}}{\varphi} \sigma_{1} d \varepsilon_{e}
\end{array}\right.
$$

To describe the change of loading path,Eq.(13)is integrated[27].Considering the simplification of numerical calculation, the equation isrewritten as:

$$
\left\{\begin{array}{l}
\sigma_{1}{ }^{\prime}=\sigma_{1} / \sigma_{1 d} \\
\sigma_{2}{ }^{\prime}=\sigma_{2} / \sigma_{1 d}
\end{array}\right.
$$

where $\sigma_{1 d}$ and $\sigma_{2 d}$ are in-plane principal stresses at the starting point of Phase II.Apparently, for the initial state of Phase II:

$$
\left\{\begin{array}{l}
\sigma_{1}^{\prime}=1 \\
\sigma_{2}^{\prime}=\alpha_{d}
\end{array}\right.
$$

Rearranging Eq. (13), the following equationis obtained,

$$
\left\{\begin{array}{l}
d \sigma_{2}^{\prime}=\left(\frac{n}{\varepsilon_{e}} \varphi-\beta_{1} \frac{\varphi_{1}}{\varphi}\right) \frac{\sigma_{1}^{\prime} d \varepsilon_{e}}{\beta_{2}} \\
d \sigma_{1}^{\prime}=\sigma_{1}^{\prime} d \varepsilon_{1}=\frac{\varphi_{1}}{\varphi} \sigma_{1}^{\prime} d \varepsilon_{e}
\end{array}\right.
$$

Therefore, the loading path of the whole Phase II can be calculated by Eqs. (15) and(16). Assuming the iteration step-size $\left(d \varepsilon_{e}\right)$ is 0.0001 , the following results can be deduced: 


$$
\left\{\begin{array}{l}
\varepsilon_{e}=\varepsilon_{e d}+\sum_{i=1}^{N-1} d \varepsilon_{e} \\
\sigma_{1}^{\prime}=1+\sum_{i=1}^{N-1} d \sigma_{1}^{\prime} \\
\sigma_{2}^{\prime}=\alpha_{d}+\sum_{i=1}^{N-1} d \sigma_{2}^{\prime} \\
\alpha=\frac{\sigma_{2}^{\prime}}{\sigma_{1}^{\prime}} \\
d \varepsilon_{1}=\frac{\varphi_{1}}{\varphi} d \varepsilon_{e} \\
d \varepsilon_{2}=\frac{\varphi_{2}}{\varphi} d \varepsilon_{e} \\
\rho=\frac{d \varepsilon_{2}}{d \varepsilon_{1}} \\
\varepsilon_{1}=\varepsilon_{1 d}+\sum_{i=1}^{N-1} d \varepsilon_{1} \\
\varepsilon_{2}=\varepsilon_{2 d}+\sum_{i=1}^{N-1} d \varepsilon_{2}
\end{array}\right.
$$

The deformation mode of Phase III is described by localized instability or macroscopic crack appearing with a precipitous drop of loading force. The realization of the plane strain state $\left(d \varepsilon_{2}=0\right)$ is taken as the condition of the occurrence of localized instability in the original C-H model. However, previous researchhasshown that the error of the theoretical prediction via $\mathrm{C}-\mathrm{H}$ model is especially large under plane stain state.Therefore, PhaseIII describing the onset of ductile fracture in forming process is identified by the modified Lou-Huh ductile fracture criterion in this research.

\subsection{The modified Lou-Huh ductile fracture criterion}

\subsubsection{Application of Hill'48 yield function}

To consider the influence ofmaterial normal anisotropy on the ductile fracture behavior of DP590 sheet,von Mises yield function is replaced by Hill'48 yield function, which is applied to combine with Lou-Huh ductile fracture criterion.The Lou-Huh model is constructed based on the mechanism of voids nucleation, growth and shear coalescence as expressed in Eq.(18).

$$
\left(\frac{2 \tau_{\max }}{\sigma_{e}}\right)^{C_{1}}\left(\frac{\langle 1+3 \eta\rangle}{2}\right)^{C_{2}} \varepsilon_{e}^{f}=C_{3} \quad\langle x\rangle= \begin{cases}x & \text { when } x \geq 0 \\ 0 & \text { when } x<0\end{cases}
$$


where $\tau_{\max }$ is the maximum shear stress, $\varepsilon_{e}^{f}$ is the equivalent plastic strain at the onset of the final fracture, $\eta$ is the stress triaxiality,and $C_{1}, C_{2}, C_{3}$ are the material constants of the ductile fracture criterion, respectively.

Since C-H model is only applicable to the stress states between uniaxial tension and equi-biaxial tension, the following relationshipsare satisfied,

$$
\begin{gathered}
\sigma_{1} \geq \sigma_{2}>\sigma_{3}=0 \\
1 / 3 \leq \eta \leq 2 / 3
\end{gathered}
$$

Under the plane stress state, $\tau_{\max }, \mu_{\sigma}$ and $\eta$ areformulated as,

$$
\begin{gathered}
\tau_{\text {max }}=\frac{\sigma_{1}-\sigma_{3}}{2}=\frac{\sigma_{1}}{2} \\
\mu_{\sigma}=\frac{2 \sigma_{2}-\sigma_{1}-\sigma_{3}}{\sigma_{1}-\sigma_{3}}=\frac{2 \sigma_{2}-\sigma_{1}}{\sigma_{1}}=2 \alpha-1 \\
\eta=\frac{\sigma_{m}}{\sigma_{e}}=\frac{\sigma_{1}+\sigma_{2}+\sigma_{3}}{3 \sqrt{\sigma_{1}^{2}-\frac{2 r}{1+r} \sigma_{1} \sigma_{2}+\sigma_{2}^{2}}}=\frac{1+\alpha}{3 \sqrt{1-\frac{2 r}{1+r} \alpha+\alpha^{2}}}
\end{gathered}
$$

where $\mu_{\sigma}$ denotes Lode parameter.

Combining Eqs.(21),(22)with Eq.(1), the following equation is gained,

$$
\frac{2 \tau_{\max }}{\sigma_{e}}=\frac{\sigma_{1}}{\sigma_{e}}=\frac{2}{\sqrt{\mu_{\sigma}^{2}+3+\left(4-\frac{8 r}{1+r}\right) \alpha}}
$$

Furthermore, to consider the change of loading path duringthe whole plastic deformation process including homogeneous deformation zoneand deformation localization zone, the modified Lou-Huh ductile fracture criterion is expressedasan integral form:

$$
\frac{1}{C_{3}} \int_{0}^{\bar{\varepsilon}_{f}}\left(\frac{2}{\sqrt{\mu_{\sigma}^{2}+3+\left(4-\frac{8 r}{1+r}\right) \alpha}}\right)^{C_{1}}\left(\frac{1+3 \eta}{2}\right)^{C_{2}} d \bar{\varepsilon}=D
$$

where the average normal anisotropic coefficient $r$ equals to 1, Eq. (25) can be simplified to the original form of Lou-Huh ductile fracture criterion with $\frac{2 \tau_{\max }}{\sigma_{e}}=\frac{\sigma_{1}}{\sigma_{e}}=\frac{2}{\sqrt{\mu_{\sigma}^{2}+3}}[18]$

Many investigators took stress triaxialityand Lode parameteras input data to calculate the material constants in the ductile fracture criterion. As $\eta$ and $\mu_{\sigma}$ varywith the 
advancement of plastic deformation, it is inappropriate to adoptthe mean values, initial values or final valuesduring the plastic forming process.According to the abovementioned analysis, the variation of stress ratio, which is obtained based on C-H model, can reflect the change of stress triaxiality and Lode parameter.Consequently, the modified Lou-Huh ductile fracture criterion combining with the variation of stress ratiois considered to characterize the effect ofthe whole loading history on the fracture behavior of DP590 sheet.

\subsubsection{Calibration of material constants}

The calculation accuracy of materials constants $C$ in ductile fracture criterion (DFC) directly affects the precision of predicted result, the accurate determination of material constants $C$ in DFC is thus critical. Considering there are three material constants in the Lou-Huh criterion: $C_{1}, C_{2}, C_{3}$, which can be calculated by at least three experimental data. Hence, three typical tensile tests including uniaxial tension, plane strain tension and equi-biaxial tensionwere conducted to obtain the equivalent plastic strains at the onsetof the final fracture, which are used as the termination conditions of iterative algorithm of C-H model.Since the loading paths of three typical tensile tests are changed during the forming process, the whole loading history described by the evolution of stress ratio with equivalent plastic strain should be considered in the determination of materials constants C.Based on the obtained loading history, the material constants in the modified Lou-Huh ductile fracture criterion can be calibrated by using the optimization algorithm as summarized in Eq. (26).

$$
\left[C_{1}, C_{2}, C_{3}\right]=\min _{C_{1}, C_{2}, C_{3}} \delta_{j} \text { where } \delta_{j}=\left|1-D_{j}\right|
$$

Here, the subscripts, $j=1,2$ and3, represent the three typical loading cases. The deviation $\delta$ denotes the discrepancy between the calculated damage valueand the unity. The damage indexDcan be numerically calculated based on Eq. (25), which will reach unity at the onset of the final fracture. Therefore, the purpose of the optimization algorithm is to make the calculateddamageindex $D_{j}$ in all cases reach unitysimultaneouslyat the time of which the fracture initiates. 


\section{Experimental procedures}

\subsection{Determination of stress-strain curve}

Since sheet metal undergoes large plastic deformation before the fracture initiates, it is necessary to determine the whole stress-strain curve.The stress-strain curve from uniaxial tensile test can only be determined before the onset ofdiffuse instability, the stress-strain relationship beyond the uniform elongation of uniaxial tensile testis usually gained by extrapolating the curve based on the selected hardening law. However, enormous deviation in prediction of flow behavior of the materialis forecasted when a unreasonable hardening function is employed [33]. To minimize this deviation, the hydraulic bulge tests are adopted to study the flow behavior of dual-phase steel sheet because the deformation uniformity of sheet metal from the hydraulic bulge test far exceeds that from uniaxial tension test. In the hydraulic bulging test, the stress state of equi-biaxial stretching can be achieved at the vertex position of sheet. Since the shape of sheet near the vertex position is considered to be spherical, its curvature radius $R$ is written as Eq. (27), which is shown inFig. 5.

$$
R=\frac{b^{2}+h^{2}}{2 h}
$$

where $b$ is the length of curvature meter spacing, and $h$ is the dome height.

In addition, circular grids with diameter of $2.5 \mathrm{~mm}$ were electroplated on the surface of sheet to record local plastic strains $\varepsilon_{1}$ and $\varepsilon_{2}$ near the vertex position of bulging-sheet. Then normal strain $\varepsilon_{3}$ is calculated according to the principle of volume constancy. With the liquid chamber pressure $p$, the curvature radius $R$ and initial thicknesst $t_{0}$ of sheet, the biaxial stresses $\sigma_{1}$ and $\sigma_{2}$ at the vertex position of bulging-sheet are deduced as:

$$
\begin{gathered}
\sigma_{1}=\sigma_{2}=\frac{R p}{2 t} \\
t=t_{0} \exp \left(-\varepsilon_{3}\right)
\end{gathered}
$$

To get as many experimental data under equi-biaxial tensile stress state as possible, 
the hydraulic bulging tests were conducted under different liquid chamber pressure $p$ until the sheet failure occurs. Considering the true stress-strain points from the hydraulic bulge tests are not accurate at low bulge curvatures, the uniaxial tensile test was adopted to describe the deformation behavior of DP590 sheet at small plastic deformation condition [34].Fig. 6shows the data obtained from uniaxial tensile test up to the uniform elongation and the achieved equivalent stress-strain data based on Hill'48 yield criterionfromthe hydraulic bulging tests. These data pointswere fitted byHollomon function,as shown in Eq. (6). It was found fromFig. 6that a satisfactory fitting result was acquiredwith hardening parametersof $k=1135 \mathrm{MPa}$ and $n=0.245$.

\subsection{Determination of the fracture limit strain}

To investigate thefracture limitof DP590 sheet, theNakajima tests were conducted.Fig. 7depictsthe schematic illustration ofdie assembly of Nakajima test. Experimental limit strains under all possiblestressstates from the uniaxial tension to the equi-biaxial tensionwere obtainedvia using different specimen shapes and lubrication conditions. The shape and geometric dimension of the specimens are alsopresented inFig. 7. The widths of arc-shaped specimens are selected as 20, 40, 60, $90,120,140,160$ and $180 \mathrm{~mm}$ with the same length of $180 \mathrm{~mm}$. Before the forming process, circular grids with diameter of $2.5 \mathrm{~mm}$ were electro-etched on the surface of sample. During the experiments, a constant blank-holder force of 300kNwas applied on the sheet metal, andthe specimens were deformed until fracturewith a constant punch velocity of $30 \mathrm{~mm} / \mathrm{min}$. Meanwhile, the circular grids on the surface of specimens were distorted into elliptic grids.

Fig. 8 illustrates the deformed specimens after Nakajima tests. It is noted that the ductile fracture of DP590 sheet takes place with moderate necking phenomenon. In this paper, to investigate the ductile fracture behavior of DP590 sheet, the fracture limit strains in the fracture zone that are obtained by extrapolating the measured strains in the edge of the fracture section are adopted. According to the investigations of Lou [2] and Ma[35], the FFLD measured by the optical measuring system is utilized to approximatethe equivalent plastic strains to fracture under the three typical loading 
cases, i.e., uniaxial tension, plane strain tension and equi-biaxial tension. In addition, it has been demonstrated by Ma et al. [36] that the loading paths prior to fracture of Nakajima tests with the arc-shaped specimen widths of 20, 90 and 180mmapproach to those from the uniaxial tension, plane strain tension and equi-biaxial tension stress states. Thus, the specimen dimensions of three calibration tests are selected as the arc-shaped widths of 20, 90 and $180 \mathrm{~mm}$ with the same length of $180 \mathrm{~mm}$. In order to ensure the accuracy of material constants, each calibration tests are tested two times with the same punch velocity of $30 \mathrm{~mm} / \mathrm{min}$.Here, the measured fracture limitstrains and corresponding equivalent plastic strainsare summarized inTable 3.

\section{Results and discussion}

\subsection{The evolutionof stress ratio $\alpha$}

According to the analysis of PhasesI and II of C-H model, the relationship between stress ratioand the equivalent plastic strainunder three typical loading cases was worked out, as demonstrated inFig. 9. It is found that the stress ratiokeeps constant during Phase I. However, in Phase II, the changing tendency of stress ratiowith the increase of the equivalent plastic strainis different for three loading cases.In the uniaxial tension condition, the stress ratiosteadily increases with the development of plastic deformation. Whereas, the stress ratioof equi-biaxial tension gradually decreases with the increase of equivalent plastic strain. The variation of stress ratioof plane strain tension is not obvious during Phase II. The diverse variationsmirror that the stress states of uniaxial tension and equi-biaxial tension do not always maintainproportional loading over the whole period, but gradually drift toward plane strain with the occurrence of load instability. But the stress state of plane strain tensionremains almost constant with plastic deformation. The second order polynomial functionwas adopted to fit the relationship betweenstress ratioand the equivalent plastic strainduring Phase II, as shown inFig. 9. 


\subsection{Comparison of predicted FFLDsto experimental result}

The effect of loading path on the fracture behavior is not taken into account in the process of the determination of thematerial constants of the original Lou-Huh ductile fracture criterion.The stress ratioof proportional loading stage is adopted for the whole loading process up to the onset of ductile fracture. Thus, the path-independent material constants in the original Lou-Huh model can be worked outviathe optimization algorithm of Eq. (26) alongthree representative loading cases. However, based on the above analysis, the loading path does notremainlinear during the deformation process.According to $\mathrm{C}-\mathrm{H}$ theory, the evolution of loading path during the whole plastic deformation process is traced by stress ratio. The path-dependentmaterial constants in the modified Lou-Huh ductile fracture criterion should be determined via thecombination of the obtained stress ratioevolution equations and the optimization algorithm of Eq.(26).The material constants of the original and modified Lou-Huh modelsare summarized in Table 4. The fracture limit strains between uniaxial tensile and equi-biaxial tensile states were calculated by using these constants, but the evolution of stress ratio of other stress states must be considered in the integral process of the modified Lou-Huh model.

The theoretical FFLDs predicted by the original and modified Lou-Huh ductile fracture criteria are compared with the experimental result, as shown in Fig. 10. Obviously, among the two ductile fracture criteria, the theoretical fracturelimit curve calculated by the modified Lou-Huhmodelis in best agreement with the experimental one, especially under the uniaxial tension and equi-biaxial tension states. Nevertheless, in plane strain tension condition, thefracture limit strain reckoned by the original Lou-Huhmodelis coincided with that calculated by the modified one.This is becausethe variation of stress ratiois not obvious, and the loading path almost remains constantin this scenario. Under other stress states except the plane strain state,the stress ratiosvary significantlywith the advancement of plastic deformation, and stress statesgradually drift toward plane strain. Therefore, on the whole,the theoretical result based on the modifiedmodelis more consistent with experimental data than that 
determined by the originalmodel.

Based on the microscopic analysis of Lou-Huh model, the void growth is represented by the function of stress triaxiality, and the coalescence of voids is described by Lode parameter.Material constants in Lou-Huh model regulate the influence of nucleation, growth and coalescence of microscopic voids on ductile fracture, which are separately summarized as follows. Firstly, the material constant $C_{1}$ adjusts the effect of Lode parameter on coalescence of voids during plastic deformation. Since $C_{1}$ from the modified Lou-Huh model is larger than that from the original model, the tendency of coalescence of voids is obviously enhanced in the modified model. Secondly, the material constant $C_{2}$ accommodates the influence of stress triaxiality on growth of voids. As $C_{2}$ is slightly larger in the modified model, the effect ofvoid growth is correspondingly increased. And lastly, the material constant $C_{3}$ just modulates the magnitude of FFLD. In original Lou-Hu model, $C_{3}$ is equal to the fracture strain of the uniaxial tensile, which is showed in Table 3 and Table 4. As for $C_{3}$ in modified Lou-Hu model, it is significantly greater than that in original model for higher theoretical FFLD.

\subsection{The analysis of ductile fracture}

From the relationship between stress ratio and the equivalent plastic strain, the evolution of stress triaxialityand Lode parametercan be derived by Eqs. (22) and (23), as shown inFig. 11. In addition, according to the forms of Eqs. (22)and(23), the change of stress triaxiality with stressratio is not obvious in larger stress ratio condition. However, Lode parameter varies evenly withstress ratio over the entire stress ratio range.For the uniaxial tension stress state, the $\eta$-value and $\mu_{\sigma}$-value remain $1 / 3$ and -1 beforeloadinstability, respectively.Then, they increase rapidly after the load instability occurs, which apparently accelerate the growth and shear coalescence of micro-voids.Li et al.[26]also came to the same conclusion by researching the fracture mechanism of Al-6061 billet.In plane strain tension condition, the diffuse instability period becomes shorter, and the $\eta$-value and $\mu_{\sigma}$-valueremain at approximately $1 / \sqrt{3}$ 
and 0 , respectively. In addition, the plane strain state $\left(\mu_{\sigma}=0\right)$ facilitates shear coalescence of voids to inducelowerequivalent plastic strain. Under equi-biaxial tension stress state, Lode parameter keeps constant until the occurrence of loadinstability, then it decreaseswith the equivalent plastic strain. However, the stress triaxiality decreases slightly after loadinstability, which is verified by Mohr et al. [20]. That means the growth of micro-voids basically remains unchanged and the coalescence of micro-voids is enhanced slightly after the load instability. In Fig. 11, the experimental fracture strains from Nakajima tests were compared with the predicted fracture locus ofDP590 sheet. The result of comparison shows that the modified Lou-Huh model has agood prediction capabilityforDP590 sheet formability.

Moreover, SEM images of fracture surfaces were taken for the three typical loading specimens to characterize the ductile fracture behavior ofDP590 sheet,as illustrated in Fig. 12. In the uniaxial tension specimen with the widthof 20mm (shown in Fig. 12 (a)), the enlarged voids are distributed in the center region ofthe fracture surface, while smaller voids can be found on the peripherydue to the intensified effect of shear deformation.Fig. 12 (b) shows the plane strain tension specimen with the width of $90 \mathrm{~mm}$, the enlarged voids are presented in a larger area, and the shear fracture occurs at the outer area of fracture surface. In the equi-biaxial tensionspecimen with the width of $180 \mathrm{~mm}$, as shown in Fig. 12 (c), the enhanced voids are located in nearly entire fracture surface area.

\section{Conclusions}

In this research, a new methodologyto predict the onset of ductile fracture of DP590 sheetwas proposed by using the modified Lou-Huh fracture criterion combined with $\mathrm{C}-\mathrm{H}$ model, which is suitable to describe the change of loading paths during the deformationprocessin the plane stress condition.The main findings were summarized as follows:

(1) The plastic deformation process was divided into three phases according to C-H model. Phase Idescribes the homogeneous deformation of sheet metal with a constant stress ratio, whilePhase IIdepicts the deformation localization of material with the 
drift of loading path,which is reflected by the change of stress ratio.Phase III is predicted by the ductile fracture criterion. During plastic deformation,the stress states of uniaxial tension and equi-biaxial tension tend toward plane strain, and thestress ratioof plane stain tension is nearly invariable.

(2) Considering the effects of material anisotropy and the whole loading history, the modified Lou-Huh ductile fracture criterion was derived based on the Hill'48 yield function and the constructed relationship between stress ratio and the equivalent plastic strain. And the material constants of the modified Lou-Huh model were calibrated by using the optimization algorithm. The whole stress-strain curve wasestablished by the true stress-strain data from uniaxial tensile test and the equivalent stress-strain data from hydraulic bulge tests.The hardening behavior beyond the uniform elongation of uniaxial tensile test was accurately described byHollomon function.

(3) The modified Lou-Huh model which takesthe change of loading path into account provided more accurate formability prediction thanthe original one, particularly in the uniaxial tension and equi-biaxial tension states. Furthermore, the growth andshear coalescence of micro-voids were correlated with the evolution of stress triaxialityand Lode parameter in the plastic deformation processbased on the analysis of SEMimages of the fracture surface.

\section{Acknowledgements}

This work was financed and supported by National Science Foundation of China (Nos.51605018 and 51275026). The authors are also very grateful to Baosteel Co., Ltd. for supplying sheet metals in the tests.

\section{References}

[1] V. Uthaisangsuk, U. Prahl, W. Bleck, Modelling of damage and failure in multiphase high strength DP and TRIP steels, Engineering Fracture Mechanics 78(3) (2011) 469-486.

[2] Y. Lou, S.J. Lim, H. Huh, Prediction of fracture forming limit for DP780 steel sheet, Metals and Materials International 19(4) (2013) 697-705.

[3] O. Björklund, A. Govik, L. Nilsson, Prediction of fracture in a dual-phase steel subjected to non-linear straining, Journal of Materials Processing Technology 214(11) 
(2014) 2748-2758.

[4] N. Park, H. Huh, J.B. Nam, C.G. Jung, Anisotropy effect on the fracture model of DP980 sheets considering the loading path, International Journal of Automotive Technology 16(1) (2015) 73-81.

[5] J.R. Rice, D.M. Tracey, On the ductile enlargement of voids in triaxial stress fields, Journal of the Mechanics \& Physics of Solids 17(3) (1969) 201-217.

[6] A.L. Gurson, Continuum Theory of Ductile Rupture by Void Nucleation and Growth: Part I-Yield Criteria and Flow Rules for Porous Media, Journal of Engineering Materials \& Technology 99(1) (1977) 297-300.

[7] V. Tvergaard, A. Needleman, Analysis of the cup-cone fracture in a round tensile bar, Acta Metallurgica 32(1) (1984) 157-169.

[8] L. Xue, Constitutive modeling of void shearing effect in ductile fracture of porous materials, Engineering Fracture Mechanics 75(11) (2008) 3343-3366.

[9] K.L. Nielsen, V. Tvergaard, Ductile shear failure or plug failure of spot welds modelled by modified Gurson model, Engineering Fracture Mechanics 77(7) (2010) 1031-1047.

[10] J. Lemaitre, A continuous damage mechanics model for ductile fracture, Journal of Engineering Materials \& Technology 107(107) (1985) 83-89.

[11] B. Meng, M.W. Fu, C.M. Fu, K.S. Chen, Ductile fracture and deformation behavior in progressive microforming, Materials \& Design 83 (2015) 14-25.

[12] J.W. Hancock, A.C. Mackenzie, On the mechanisms of ductile failure in high-strength steels subjected to multi-axial stress-states, Journal of the Mechanics \& Physics of Solids 24(2-3) (1976) 147-160.

[13] G.R. Johnson, W.H. Cook, Fracture characteristics of three metals subjected to various strains, strain rates, temperatures and pressures, Engineering Fracture Mechanics 21(1) (1985) 31-48.

[14] M.S. Mirza, D.C. Barton, P. Church, The effect of stress triaxiality and strain-rate on the fracture characteristics of ductile metals, Journal of Materials Science 31(2) (1996) 453-461.

[15] Y. Bai, T. Wierzbicki, Application of extended Mohr-Coulomb criterion to ductile fracture, International Journal of Fracture 161(1) (2009) 1-20.

[16] K. Danas, P. Ponte Castañeda, Influence of the Lode parameter and the stress triaxiality on the failure of elasto-plastic porous materials, International Journal of Solids and Structures 49(11-12) (2012) 1325-1342.

[17] M. Brünig, S. Gerke, V. Hagenbrock, Micro-mechanical studies on the effect of the stress triaxiality and the Lode parameter on ductile damage, International Journal of Plasticity 50 (2013) 49-65.

[18] Y. Lou, H. Huh, Prediction of ductile fracture for advanced high strength steel with a new criterion: Experiments and simulation, Journal of Materials Processing Technology 213(8) (2013) 1284-1302.

[19] K. Pack, K. Ahn, H. Huh, Y. Lou, Fracture modelling of DP780 sheets using a hybrid experimental-numerical method and two-dimensional digital image correlation, International Journal of Materials \& Product Technology 48(1/2/3/4) (2014) 34-46.

[20] D. Mohr, S.J. Marcadet, Micromechanically-motivated phenomenological 
Hosford-Coulomb model for predicting ductile fracture initiation at low stress triaxialities, International Journal of Solids and Structures 67-68(0) (2015) 40-55.

[21] A.G. Atkins, Y.W. Mai, Elastic \& plastic fracture, Chichester: Ellis Horwood, 1985.

[22] Z. Marciniak, K. Kuczyński, Limit strains in the processes of stretch-forming sheet metal, International Journal of Mechanical Sciences 9(9) (1967) 609-620.

[23] J. Ding, C. Zhang, X. Chu, G. Zhao, L. Leotoing, D. Guines, Investigation of the influence of the initial groove angle in the $\mathrm{M}-\mathrm{K}$ model on limit strains and forming limit curves, International Journal of Mechanical Sciences 98 (2015) 59-69.

[24] P.A. Friedman, J. Pan, Effects of plastic anisotropy and yield criteria on prediction of forming limit curves, International Journal of Mechanical Sciences 42(1) (2000) 29-48.

[25] L.Y. Qian, G. Fang, P. Zeng, Q. Wang, Experimental and numerical investigations into the ductile fracture during the forming of flat-rolled 5083-O aluminum alloy sheet, Journal of Materials Processing Technology 220(0) (2015) 264-275.

[26] H. Li, M.W. Fu, J. Lu, H. Yang, Ductile fracture: Experiments and computations, International Journal of Plasticity 27(2) (2011) 147-180.

[27] G.N. Chen, S.G. Hu, New concept of forming limit curve, Journal of Mechanical Engineering 30(02) (1994) 82-86.

[28] G.N. Chen, Damage, Instability and Construction of Forming Limit Curve in Sheet Metal Stretch Forming, Beihang University, Beijing, 1991.

[29] Y. Xie, Research on limit strain diagram and limit stress diagram under complex loading paths in sheet metal forming, Beihang University, Beijing, 2004.

[30] ISO, 2014. ISO 16842:2014: Metallic materials - sheet and strip - biaxial tensile testing method using a cruciform test piece.

[31] A. Considere, Ann Ponts Chausses 9 (1885) 574-775.

[32] A. Chamanfar, R. Mahmudi, Effect of specimen geometry, gage length, and width measurement locations on plastic strain ratio ( $\mathrm{R}$-value) in sheet metals, Metallurgical \& Materials Transactions A 37(12) (2006) 3477-3487.

[33] J.H. Sung, J.H. Kim, R.H. Wagoner, A plastic constitutive equation incorporating strain, strain-rate, and temperature, International Journal of Plasticity 26(12) (2010) 1746-1771.

[34] B.A. Behrens, A. Bouguecha, M. Vucetic, I. Peshekhodov, Characterisation of the quasi-static flow and fracture behaviour of dual-phase steel sheets in a wide range of plane stress states, Archives of Civil and Mechanical Engineering 12(4) (2012) 397-406.

[35] B. Ma, Z.G. Liu, Z. Jiang, X. Wu, K. Diao, M. Wan, Prediction of forming limit in DP590 steel sheet forming: An extended fracture criterion, Materials \& Design 96 (2016) 401-408.

[36] B. Ma, K. Diao, X. Wu, X. Li, M. Wan, Z. Cai, The effect of the through-thickness normal stress on sheet formability, Journal of Manufacturing Processes 21 (2016) 134-140. 
Table Captions and then Figures

Table 1 Chemical compositions of DP590 sheet.

Table 2 Mechanical properties of DP590 sheet.

Table 3 The fracture strains of DP590 sheet under different stress states.

Table 4 Material constants of different ductile fracture criteria.

Fig. 1 True stress-strain curves of DP590 sheet by tensile test under three directions.

Fig. 2 Research procedure.

Fig. 3 Schematic diagram of the Phases I and II of C-H model.

Fig. 4 Comparison between the experimental and theoretical yield loci of DP590 sheet.

Fig. 5 The schematic diagram of the determination of sheet curvature radius R.

Fig. 6 Comparison between the experimental data and fitting curve for DP590 sheet.

Fig. 7 The schematic illustration of die assembly and specimens dimensions for the Nakazima test.

Fig. 8 The formed specimens of DP590 sheet.

Fig. 9 The evolution of stress ratio with the equivalent plastic strain: (a) uniaxial tension, (b) plane stain tension and (c) equi-biaxial tension.

Fig. 10 Comparison of FFLDs predicted by different ductile fracture criteria with the experimental one.

Fig. 11 The evolution of stress triaxiality and Lode parameter with equivalent plastic strain between the uniaxial tension and equi-biaxial tension states.

Fig. 12 SEM images of fracture surface: (a) uniaxial tension, (b) plane strain tension and (c) equi-biaxial tension. 


\section{${ }^{*}$ Graphical Abstract}
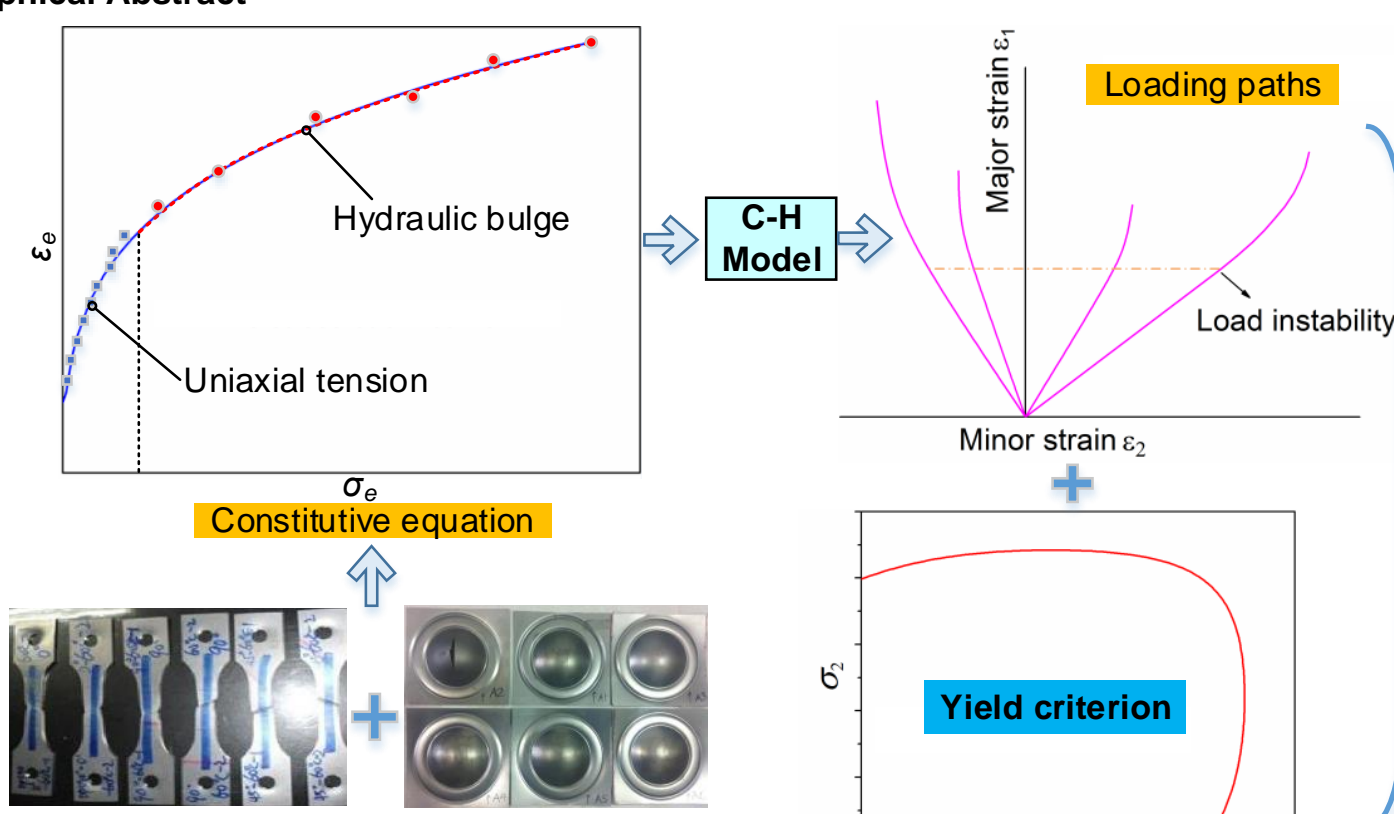

Uniaxial tension tests
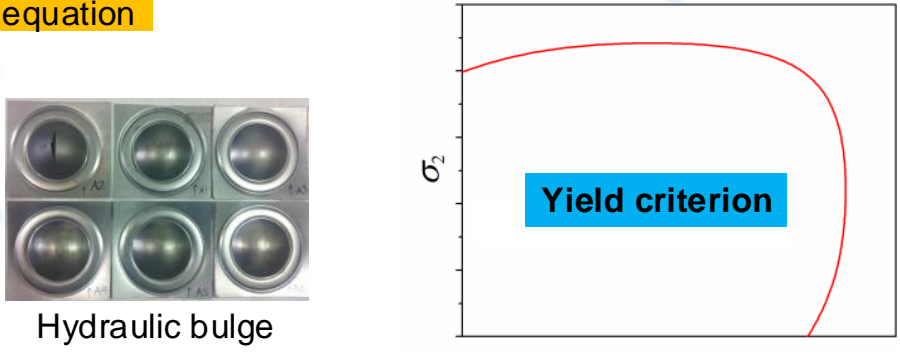

$\sigma_{1}$

Predicted FFLD

Minor strain $\varepsilon_{2}$

- The evolution of $\eta$ and $\mu_{\sigma}$ with $\varepsilon_{o}$ - The path of stress state 3D fracture locus of DP 590 sheet Lou-Huh criterion

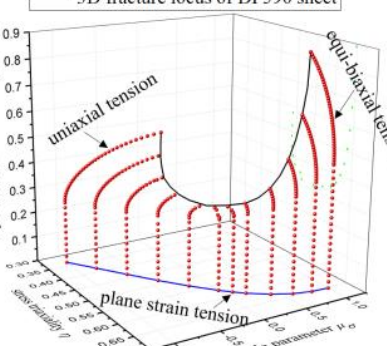

Evolution rule 


\section{List of Tables}

Table 1 Chemical compositions of DP590 sheet.

\begin{tabular}{ccccc}
\hline \multicolumn{5}{c}{ Nominal composition $($ wt.\%) } \\
\hline $\mathrm{C}$ & $\mathrm{Mn}$ & $\mathrm{Si}$ & $\mathrm{S}$ & $\mathrm{P}$ \\
0.068 & 1.61 & 0.447 & 0.002 & 0.011 \\
\hline
\end{tabular}

Table 2 Mechanical properties of DP590 sheet.

\begin{tabular}{cccccc}
\hline \multirow{2}{*}{ Material } & $\begin{array}{c}\text { Angle to the } \\
\text { Rolling Direction }\end{array}$ & $\sigma_{0.2} / \mathrm{MPa}$ & $\sigma_{\mathrm{b}} / \mathrm{MPa}$ & $n^{*}$ & $r$-value \\
\hline \multirow{2}{*}{ DP590 } & $0^{\circ}$ & 398 & 631 & 0.177 & 0.963 \\
& $45^{\circ}$ & 404 & 645 & 0.170 & 0.815 \\
& $90^{\circ}$ & 388 & 630 & 0.172 & 1.096 \\
\hline
\end{tabular}

Table 3 The fracture strains of DP590 sheet under different stress states.

\begin{tabular}{cccc}
\hline $\begin{array}{c}\text { Fracture } \\
\text { strain }\end{array}$ & Uniaxial tension & $\begin{array}{c}\text { Plane strain } \\
\text { tension }\end{array}$ & $\begin{array}{c}\text { Equi-biaxial } \\
\text { tension }\end{array}$ \\
\hline$\varepsilon_{1}$ & 0.569 & 0.282 & 0.486 \\
$\varepsilon_{2}$ & -0.194 & 0.017 & 0.420 \\
$\varepsilon_{e}$ & 0.576 & 0.331 & 0.889 \\
\hline
\end{tabular}

Table 4 Material constants of different ductile fracture criteria.

\begin{tabular}{cccc}
\hline & $C_{1}$ & $C_{2}$ & $C_{3}$ \\
\hline Modified Lou-Huh model & 7.0864 & -0.5036 & 0.6956 \\
Original Lou-Huh model & 6.3285 & -0.7865 & 0.5760 \\
\hline
\end{tabular}


Fig. 2

\section{The Lou-Huh fracture criterion considering loading path}

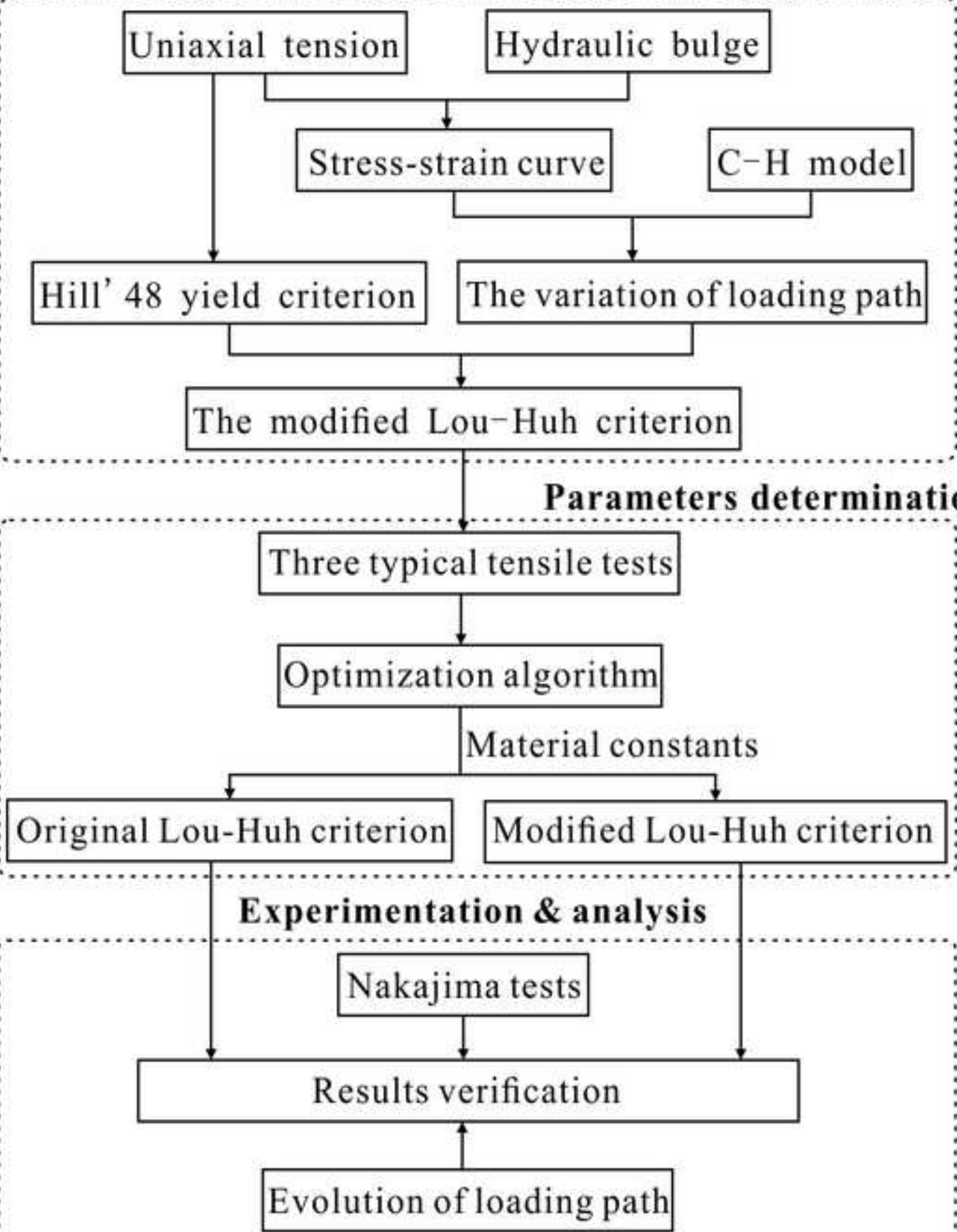




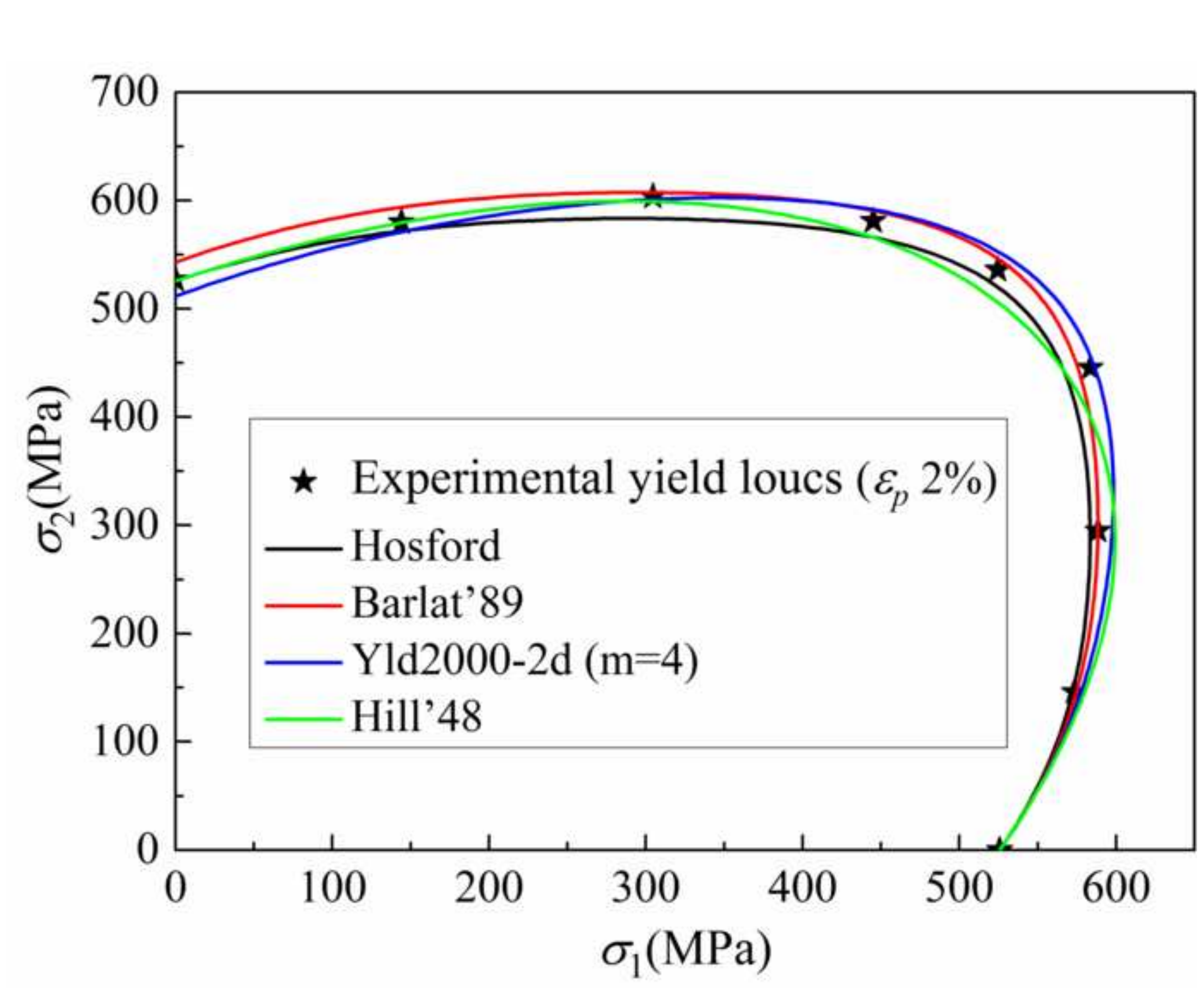




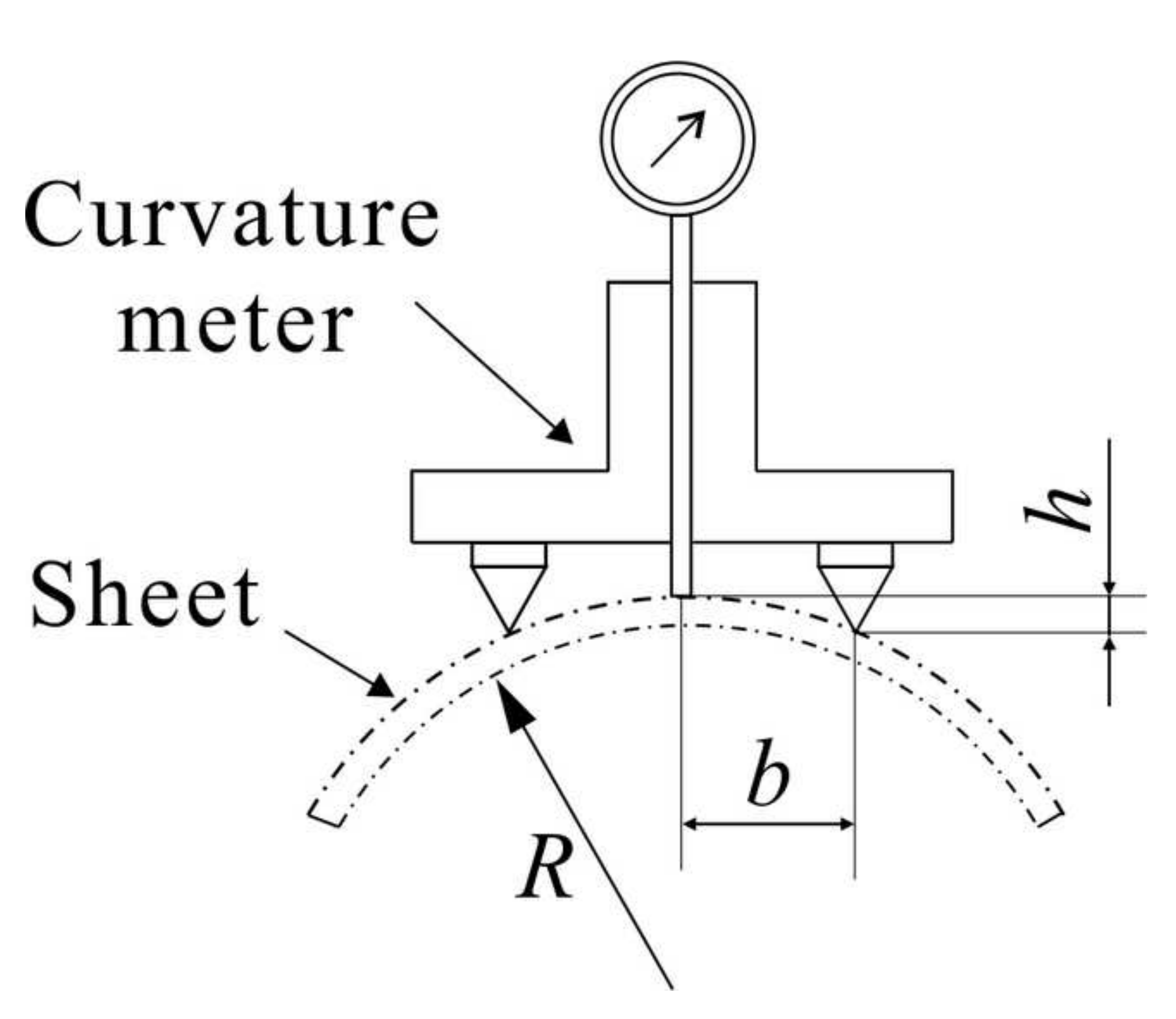

Curvature meter

Sheet

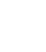
. 


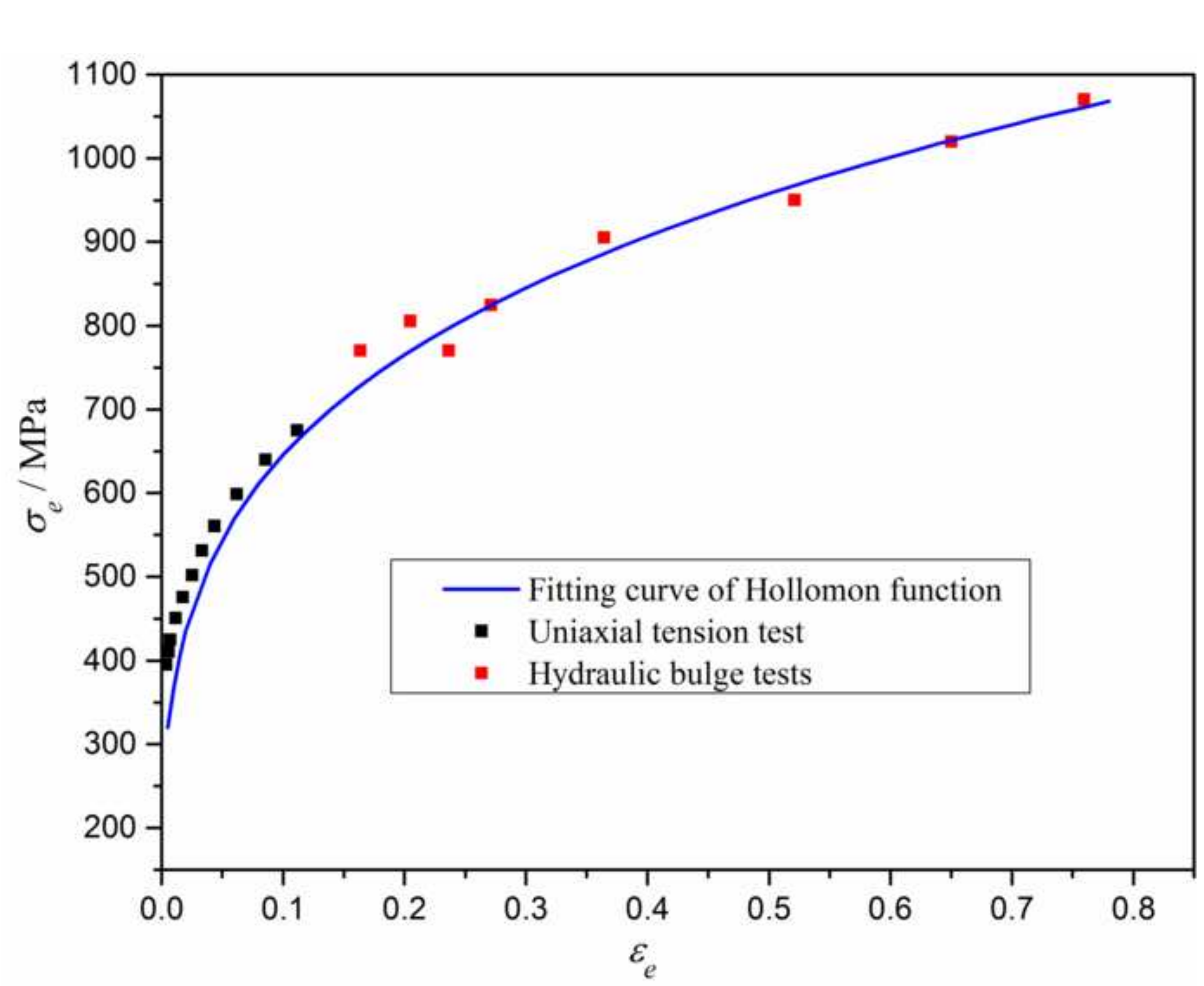



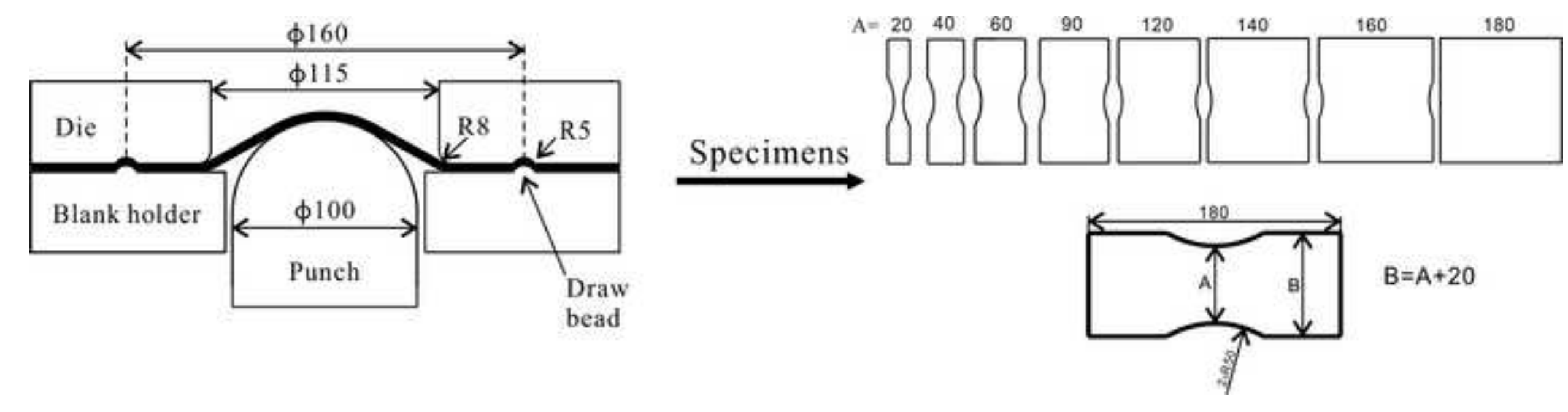

$B=A+20$

Fig. 7

$\stackrel{\text { Specimens }}{\longrightarrow}$ 

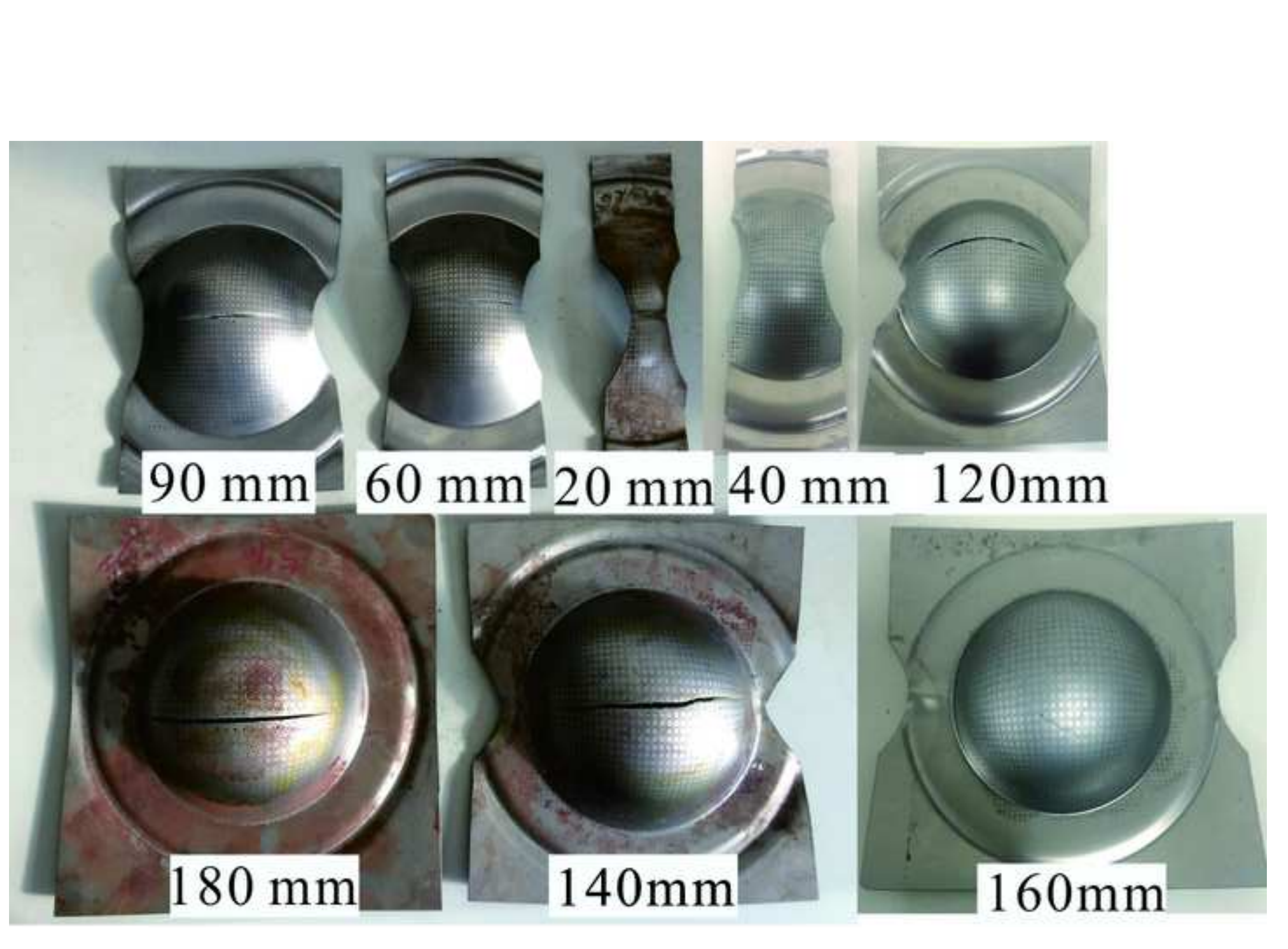

\section{m $120 \mathrm{~mm}$}
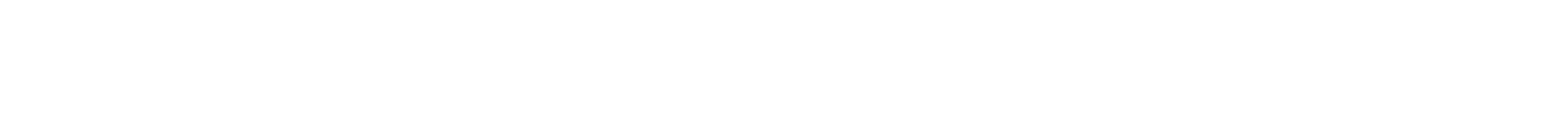
(a)

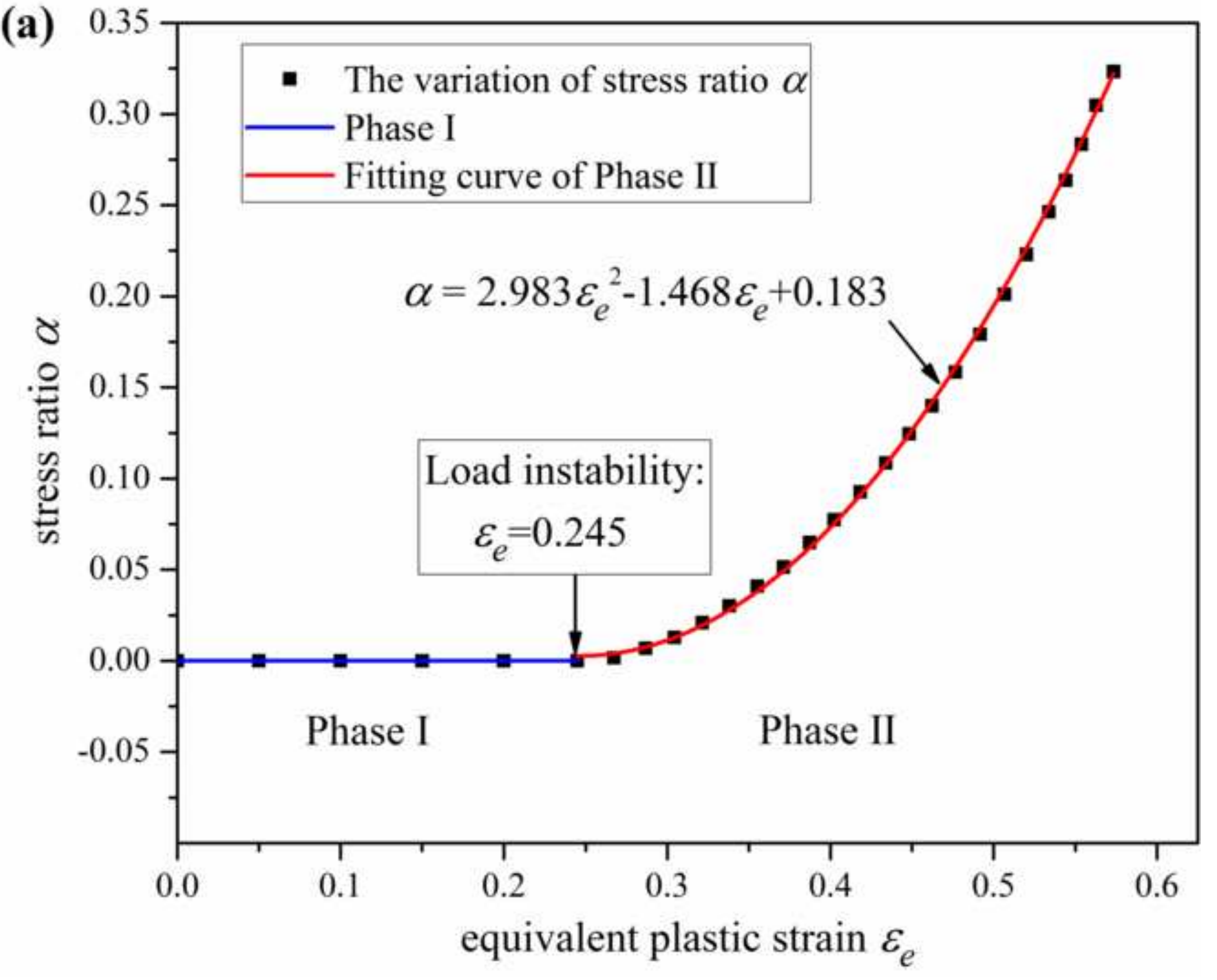




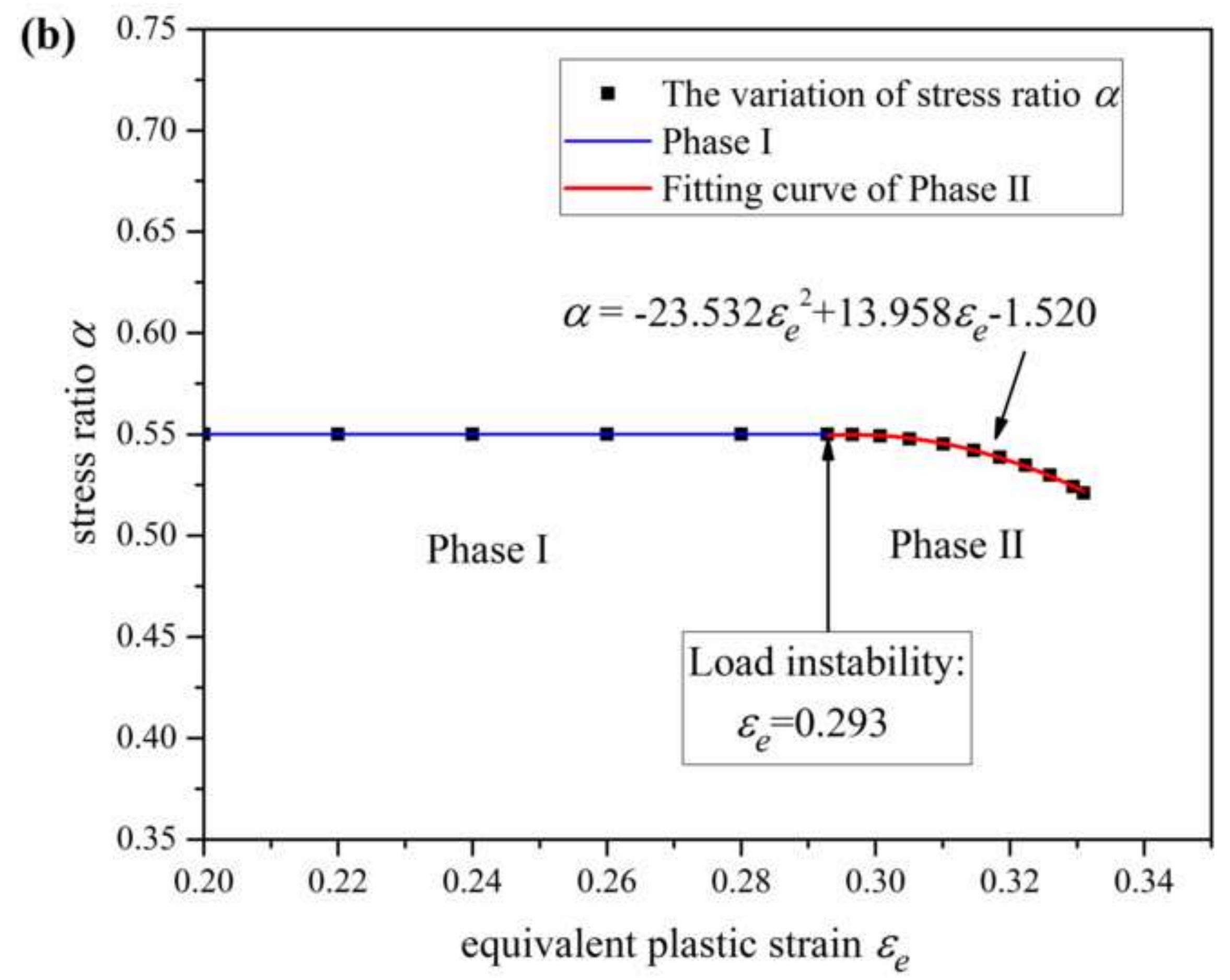


(c)

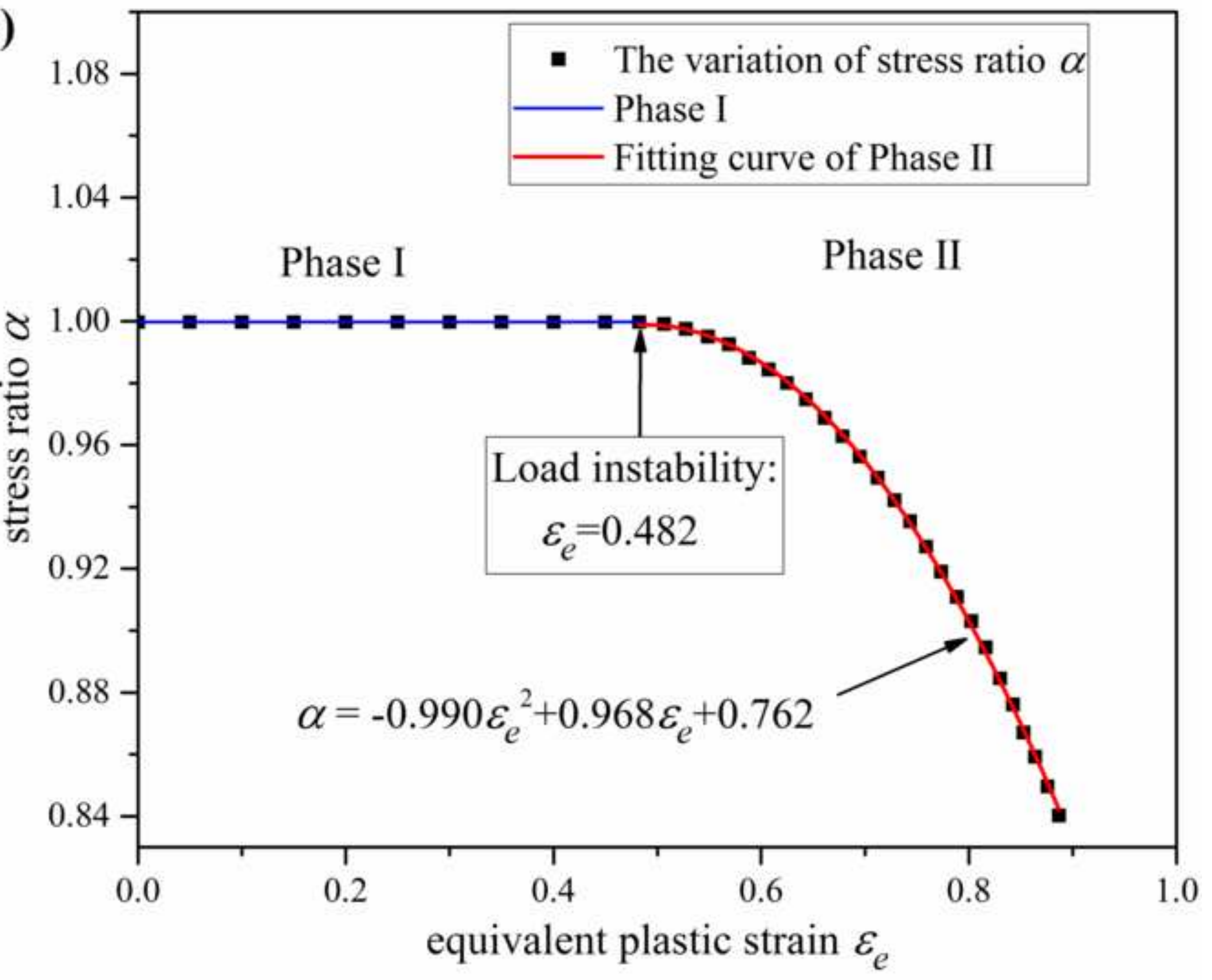




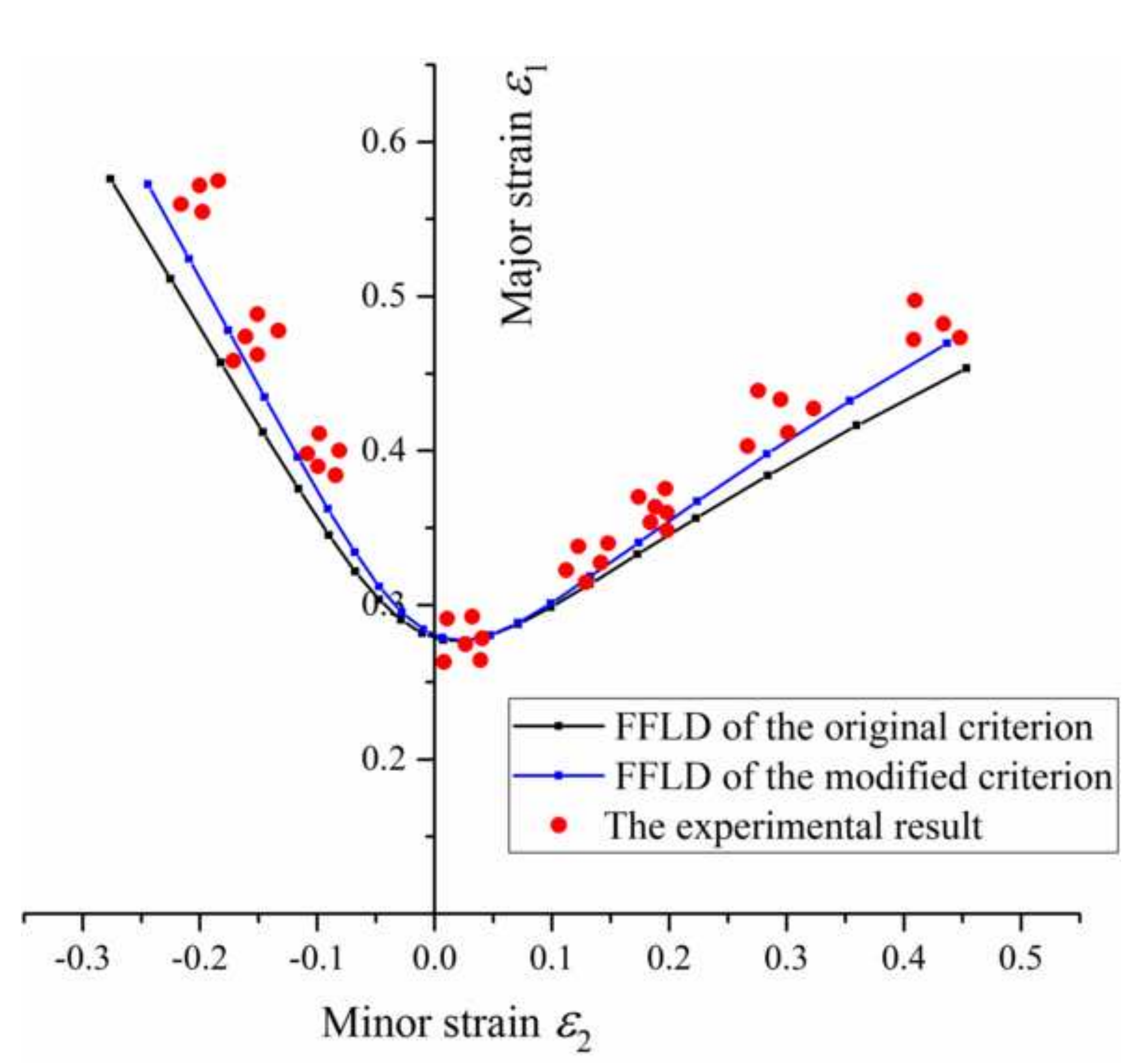




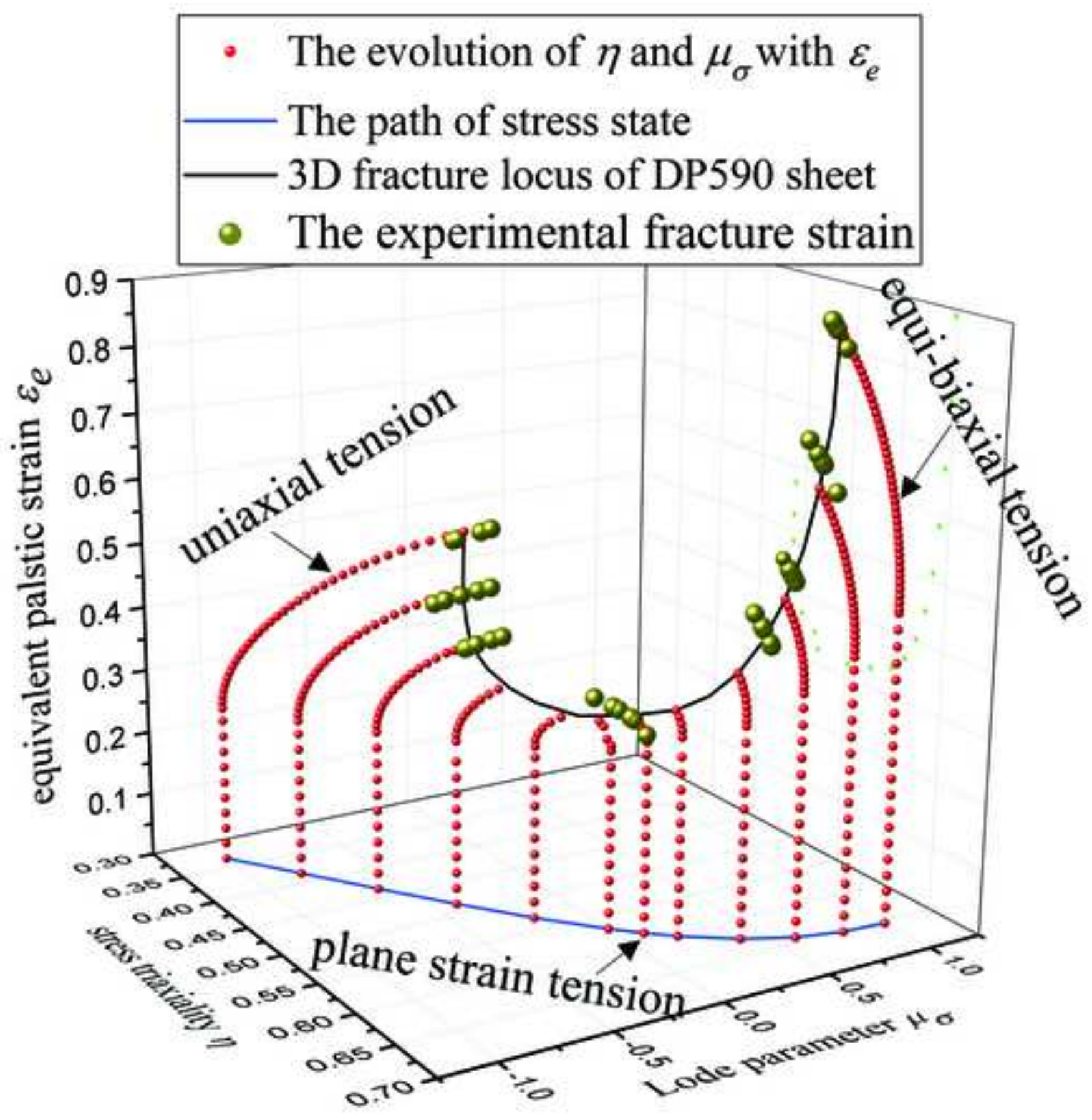



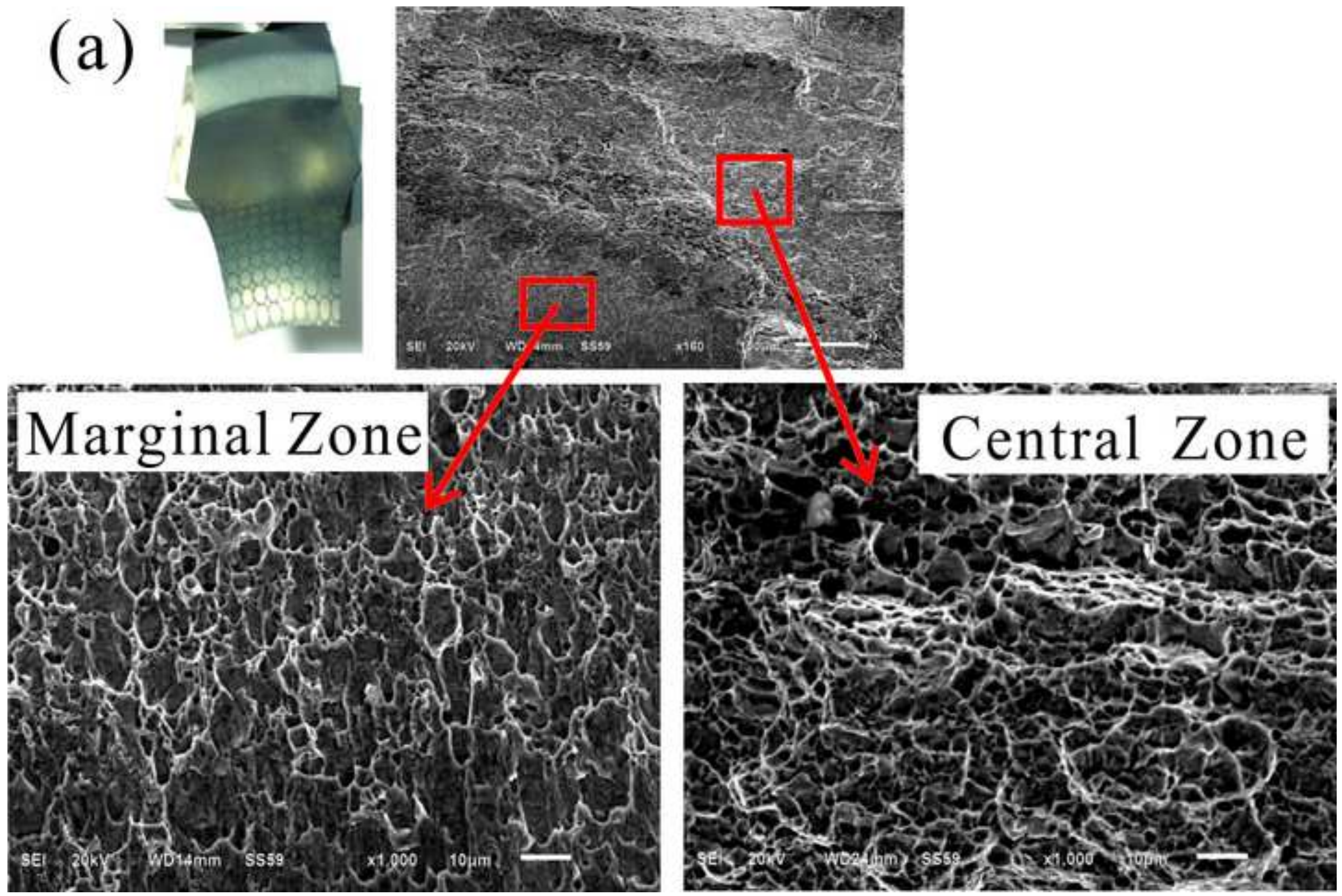

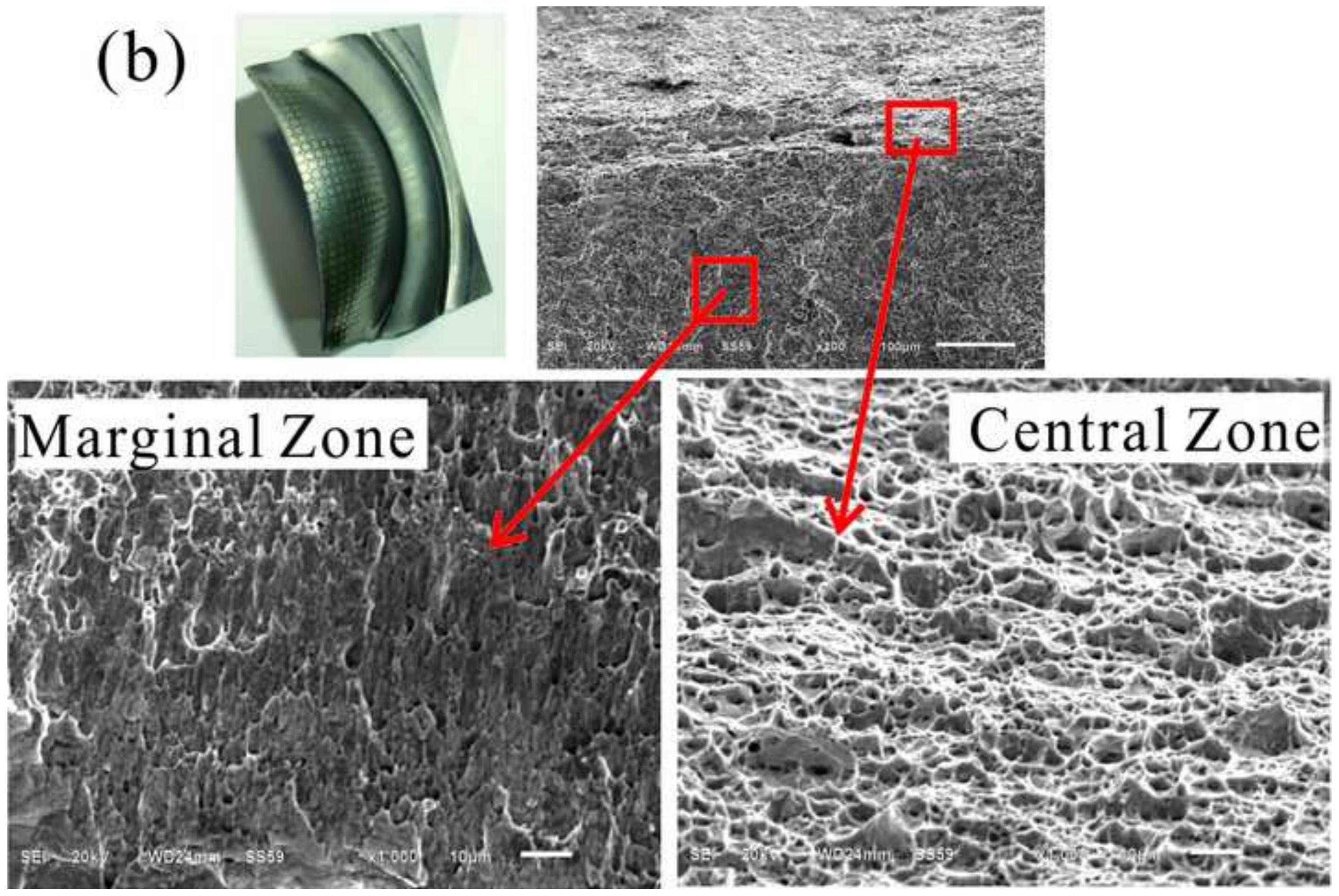

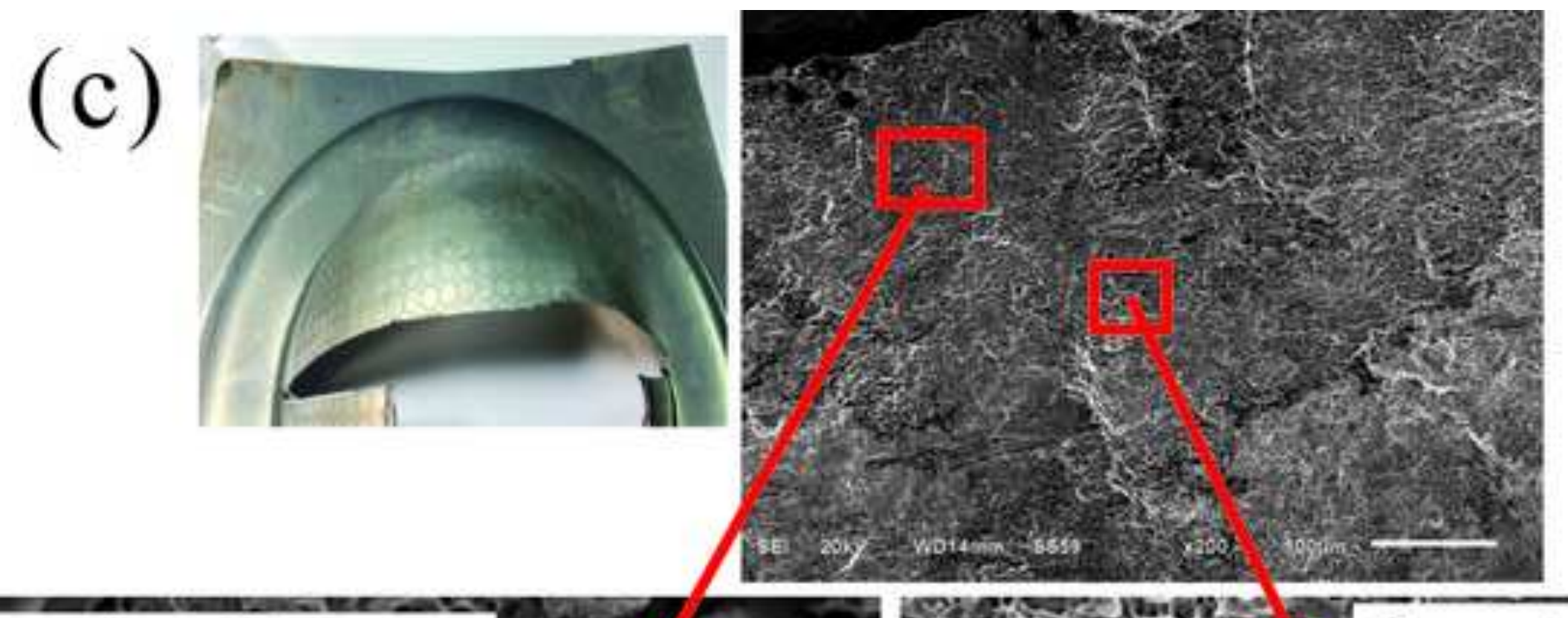

\section{Marginal Zone}

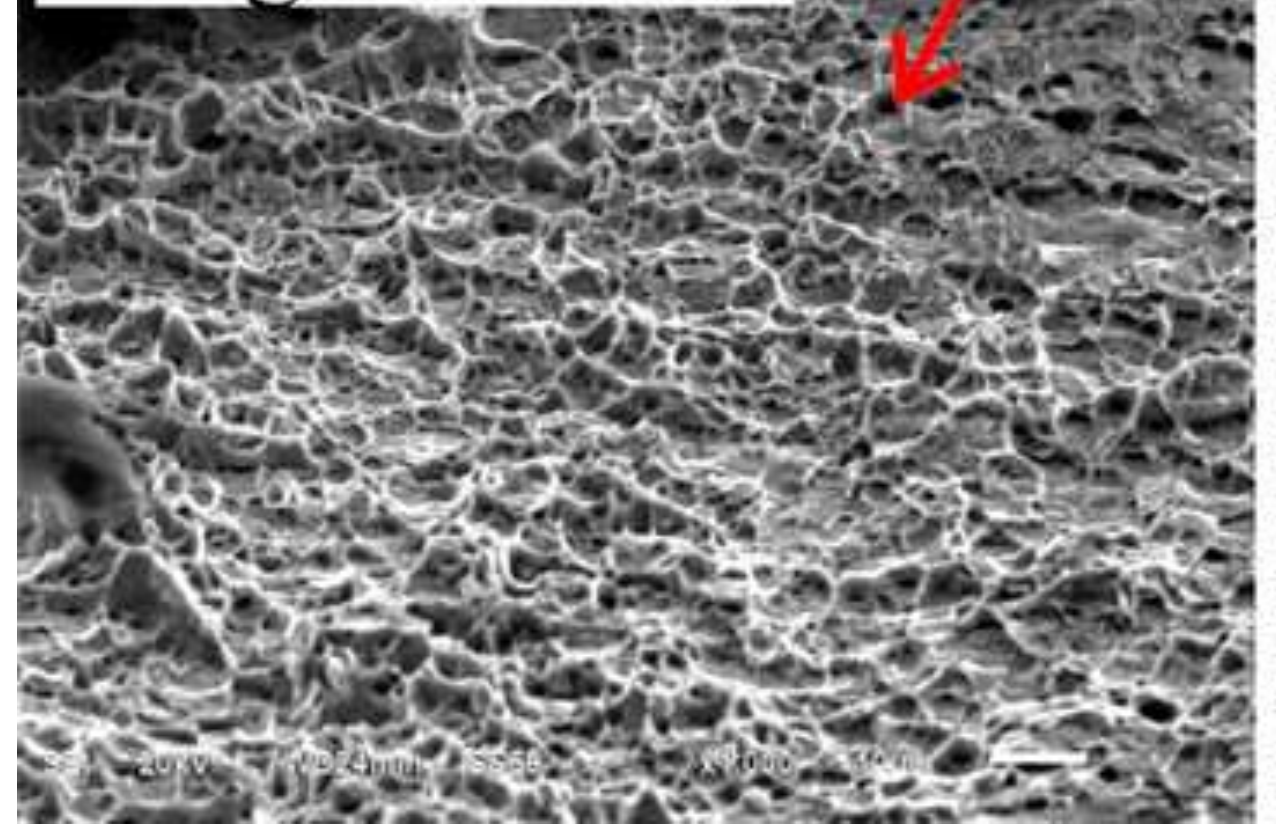

Central Zone

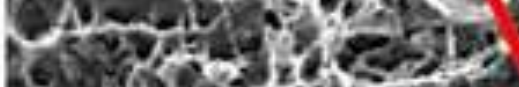

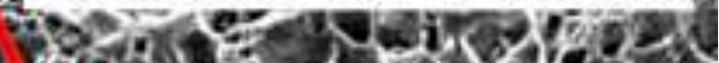
H. P.j.

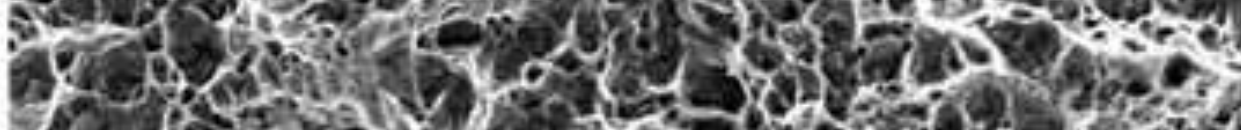
9.2.

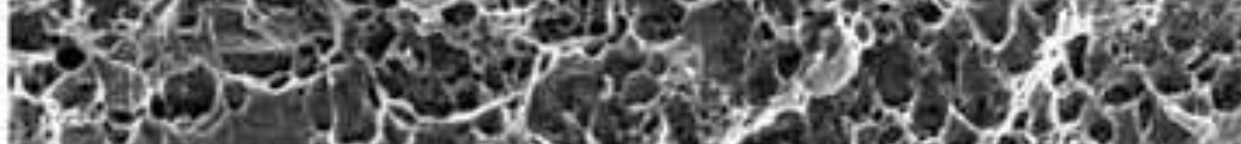
ST.5.

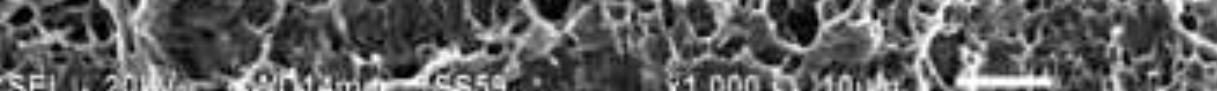

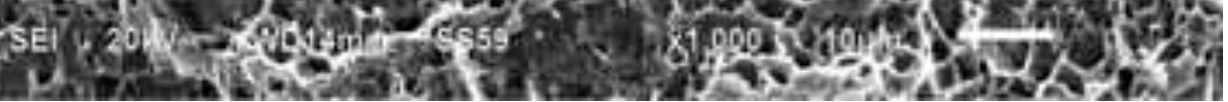

